\title{
Promoting axon regeneration by enhancing the non- coding function of the injury-responsive coding gene Gpr151
}

\section{Bohm Lee}

Korea University

Jinyoung Lee

Korea University

Yewon Jeon

Korea University https://orcid.org/0000-0002-7082-1969

Hyemin Kim

Korea University

Minjae Kwon

Korea University

Jung Eun Shin

Dong-A University, College of Medicine

Yongcheol Cho ( $\triangle$ ycho77@korea.ac.kr)

Korea University https://orcid.org/0000-0003-2356-7125

\section{Article}

Keywords: 5'UTR, axotomy, axon regeneration, RNA-binding protein, translation, GPR151, single-exon gene, CSDE1, dorsal root ganglion, RiboTag

Posted Date: March 10th, 2021

DOl: https://doi.org/10.21203/rs.3.rs-269886/v1

License: (c) (1) This work is licensed under a Creative Commons Attribution 4.0 International License. Read Full License 
4 Bohm Lee ${ }^{\# 1}$, Jinyoung Lee ${ }^{\# 1}$, Yewon Jeon ${ }^{\# 1}$, Hyemin Kim ${ }^{1}$, Minjae Kwon ${ }^{1}$, Jung Eun Shin ${ }^{1,2}$ and Yongcheol Cho*1

$7 \quad{ }^{1}$ Department of Life Sciences, Korea University, Seoul 02841, Republic of Korea

$8{ }^{2}$ Department of Molecular Neuroscience, Dong-A University College of Medicine, Busan 49201,

9 Republic of Korea

11 \#These authors contributed equally to this work.

13 *Correspondence to: Yongcheol Cho, Department of Life Sciences, Korea University, Anam-ro

14 145, Seongbuk-gu, Seoul 02841, Republic of Korea. Phone: +82 23920 4727, Email:

15 ycho77@korea.ac.kr 
Gene expression profiling in response to nerve injury has been mainly focused on protein

20 functions of coding genes to understand mechanisms of axon regeneration and to identify targets

21 of potential therapeutics for nerve repair. However, the protein functions of several highly injury-

22 induced genes including Gpr151 for regulating the regenerative ability remain unclear. Here we 23 present an alternative approach focused on non-coding functions of the coding genes, which led 24 to the identification of the Gpr151 RNA function as a molecular sponge via its interaction with RNA25 binding proteins such as CSDE1. Gpr151 promotes axon regeneration by the function of its 5'26 untranslated region (5'UTR) and expression of an engineered form of the $5^{\prime}$ UTR improves 27 regenerative capacity in vitro and in vivo in both sciatic nerve and optic nerve injury models. Our 28 data suggest that searching injury-induced coding genes potentially functioning by their non-coding regions is required for the RNA-based gene therapy for improving axon regeneration.

Keywords: 5'UTR, axotomy, axon regeneration, RNA-binding protein, translation, GPR151, single-exon gene, CSDE1, dorsal root ganglion, RiboTag 
Introduction

Neurons in the peripheral nervous system (PNS) activate the intrinsic regeneration program after axons are injured, a process that is controlled by the expression of injury-responsive genes ${ }^{1-6}$. Comparative analysis of transcriptomic data between naïve and regenerating sensory neurons in dorsal root ganglia (DRG) has revealed a number of differentially expressed genes (DEGs), within which there is a subgroup of regeneration-associated genes that are required for successful regeneration ${ }^{7,8}$. However, the molecular mechanisms of the particular regenerationassociated genes involved in the regulation of regenerative potential have not been clearly delineated.

Functional analysis of protein-coding DEGs is generally regarded as a reliable strategy coding mRNA is directed to ribosome complexes if it is believed that the function of DEGs results primarily from the resulting proteins. However, with respect to the IRGs, several reports have shown a poor correlation between their mRNA and protein levels ${ }^{9-12}$, indicating that it is necessary to study the differentially expressed mRNA without the assumption that their function as regeneration-associated genes is dependent on their protein products. Therefore, monitoring the fate of the mRNA itself may be the primary route to correctly understanding how neurons alter their physiology to enter a regenerative state via DEGs ${ }^{13-16}$.

RNA-binding proteins (RBPs) play various roles including the regulation of RNA for its stability, translational efficiency, modification, localization and intermolecular interaction ${ }^{17,18}$. RBPs such as the CELF family protein UNC-75 affect axon regeneration in C. elegans via regulating alternative splicing and the Zipcode-binding protein ZBP1 can promote nerve regeneration in mice by regulating axonal mRNA transport ${ }^{19,20}$. Recent studies have shown that mRNA differentially expressed by specific cues can be directed to RBPs and modulate their regulatory functions ${ }^{21,22}$. These reports raise a hypothesis that the injury-dependent mRNA may affect the regenerative program by regulating RBPs independently from the function of its translated protein. regeneration paradigm based on their ribosome-association efficiency using RiboTag mice after 
62 axonal injury ${ }^{23}$. We found that a group of injury-responsive genes exhibited no increase in their 63 ribosome-association efficiency even when their mRNA was dramatically upregulated after axonal 64 injury, supporting potential non-coding functions of these mRNA. Of these genes, Gpr151 encodes 65 an orphan G protein-coupled receptor (GPCR) that is implicated in neuropathic pain and nicotine 66 addiction ${ }^{24-26}$. Because Gpr151 is a single-exon protein-coding gene, it was selected to explore 67 the mRNA function by examining a single form of transcript, avoiding a need to consider 68 alternatively spliced isoforms. We found that the 5' untranslated region (5'UTR) of Gpr151 mRNA 69 promotes axon regeneration and identified RBPs interacting with the 5'UTR, including CSDE1, which was found to be a negative regulator of axonal regrowth in vitro. Moreover, we found that expressing an engineered form of the 5'UTR showed improved CSDE1-association and enhanced axon regeneration both in vitro and in vivo. Overexpression of the engineered 5'UTR did not significantly change the transcriptomic profiles but instead modulated the pool of CSDE1associated RNA and promoted the release of RNA from CSDE1, including ribosomal proteinencoding mRNA. Finally, we retrospectively re-analyzed our previous transcriptomic data to present another example of injury-responsive mRNA with the non-coding function, finding that Sox11 mRNA is potentially involved in regulating axon regeneration. In this study, we introduce a new approach to DEG analysis by incorporating ribosome-association efficiency data from an axon regeneration paradigm and uncover the role of protein-coding mRNA as a biological modulator of the RBP function. 
Results

\section{Gpr151 is an injury-responsive protein-coding gene that is not directed to ribosome}

To identify regeneration-associated genes (RAGs) regulating regeneration by their noncoding functions, RiboTag mice were crossed with Advillin-Cre mice and utilized to specifically isolate the ribosome complex-bound RNA from the dorsal root ganglia (DRG) with or without sciatic nerve axotomy (Figures 1A, 1B and S1) ${ }^{8,23,27}$. Comparative analysis between the whole transcriptome and the ribosome-bound RNA showed that a large portion of upregulated coding genes was not directed to ribosome complex, suggesting that non-coding functions of these need to be investigated (Figure 1C). Among them, we selected Gpr151 as a model gene, an orphan G protein-coupled receptor that mediates nicotine sensitivity and neuropathic pain ${ }^{24,26,28,29}$. While Gpr151 upregulation after nerve injury has been reported by several transcriptome studies using DRG tissues 12-16, its role in the regulation of axon regeneration remains unknown ${ }^{30-34}$. We found that Gpr151 mRNA was dramatically upregulated with no changes in the ribosomeassociation after sciatic nerve injury (Figure 1D). Moreover, the average FPKM read count of Gpr151 reached over 2,000 at 24 hours after injury with a further increase at 72 hours, indicating the abundance of this RNA (Figure S2) 13. Western blot analysis, qPCR analysis, fluorescence in situ hybridization (FISH) and immunohistochemistry (IHC) data consistently supported the findings obtained by RNA-sequencing and bioinformatic analysis. While nerve injury greatly induces the Gpr151 RNA levels, Gpr151 protein levels are not upregulated by nerve injury but instead downregulated significantly (Figures 1E, 1F, 1G and 1H). These results showed that Gpr151 was the most upregulated and abundant injury-responsive gene with little association to ribosome and was suitable for studying the non-coding function of a coding RAG for regulating axon regeneration. In addition to its injury responses, Gpr151 is a single-exon gene and therefore it allows us to trace a single transcript form without considering alternatively spliced isoforms. 

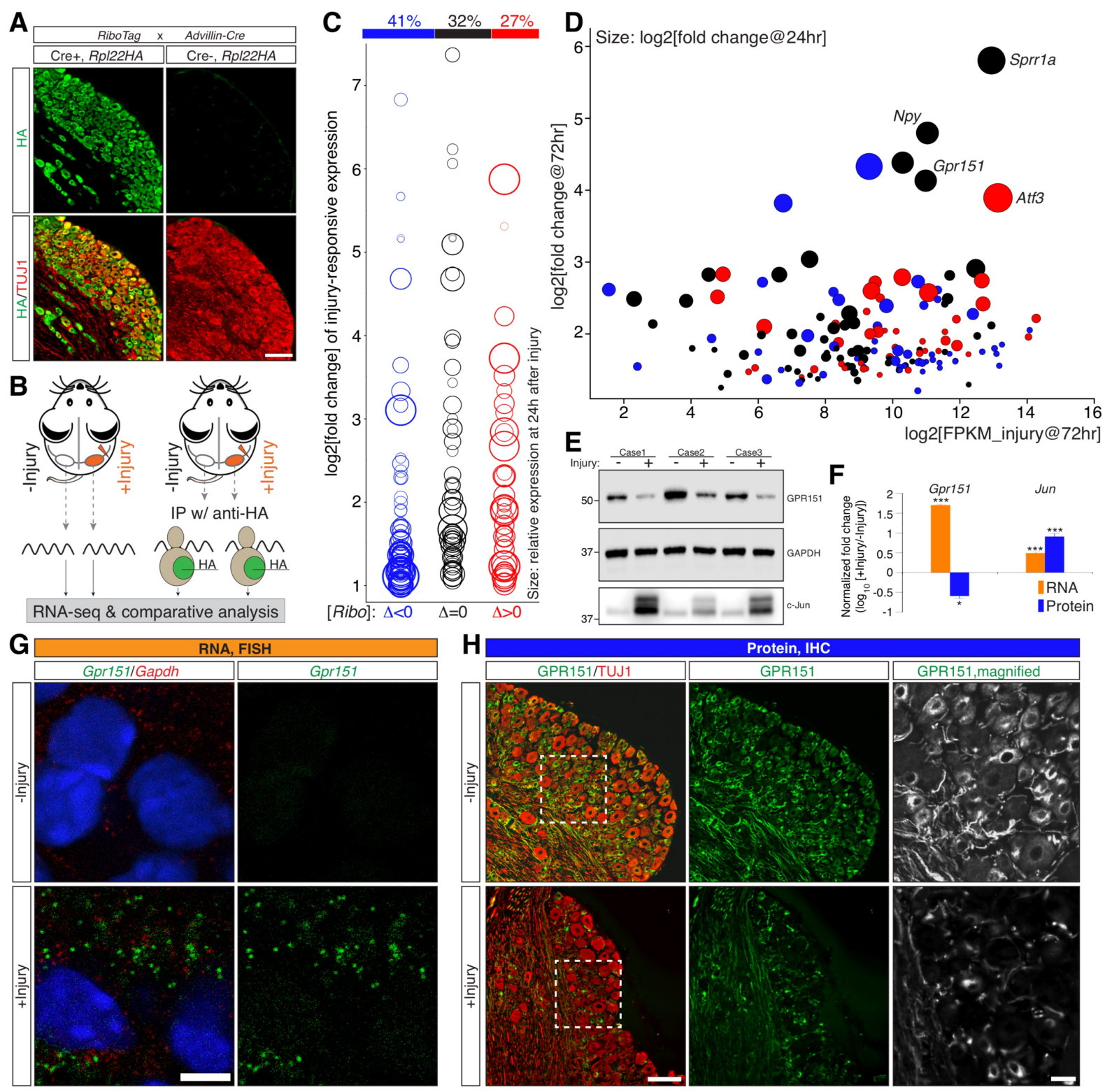

Figure 1. Gpr151 is the most upregulated and abundant injury-responsive single-exon gene that is not directed to ribosome. (A) Advillin-Cre line crossed with RiboTag mice expresses HARp/22 specifically in DRG neurons (L4 DRG sections immunostained with anti-HA and TUJ1 antibodies). Scale, $100 \mu \mathrm{m}$.

(B) Comparative analysis of gene expression and the ribosomeassociation. IP, immunoprecipitation.

(C) Differential expression (Log2 reads[@injured / @uninjured]) plotted against differential ribosome-association ([Ribo]s = reads[@injured@uninjured]). The size of circle indicates the relative expression level at 24 hours after injury. (D) 
$1183 \mathrm{D}$ plot of illumina sequencing results from the reference ${ }^{31}$ with $\mathrm{x}$-axis of $\log _{2}[\mathrm{FPKM}$ at 72 hours 119 after injury] and $y$-axis of $\log _{2}$ [fold changes at 72 hours after injury]. The bubble sizes indicate $120 \log 2$ [fold changes at 24 hours]. (E) Western blot analysis of L4,5 DRG tissues with or without 121 sciatic nerve injury. (F) Relative levels of $\log _{10}[R N A$ or protein], respectively $(n=3$; mean $\pm S E M$; $122{ }^{*} p<0.05,{ }^{* * *} p<0.001$ by $t$-test). (G) FISH analysis of L4 DRG sections with probes to Gpr151 and 123 Gapdh and DAPI. Scale, $5 \mu \mathrm{m}$. (H) Immunohistochemistry of L4 DRG sections prepared at 24 124 hours after sciatic nerve injury, stained with anti-GPR151 antibody (green) and TUJ1 antibody 125 (red). Scale bar, $100 \mu \mathrm{m}$. 


\section{Gpr151 protein-null mouse displayed no impairment of axon regeneration}

To investigate the role of Gpr151 for axon regeneration, we employed Gpr151-targeted mutant mice (KO) in which the Gpr151 CDS was disrupted by a LacZ cassette to abolish Gpr151 protein production. However, the KO mice expressed mutant mRNA (Gpr151-UTR-LacZ) with the wild type 5'UTR (Figure 2A). First, we tested the injury-responsive upregulation of the normal and mutant Gpr151 transcripts from the DRG tissue of the control and KO mice, respectively at 1 and 3 days after introducing axonal injury. We found that the levels of Gpr151-UTR-LacZ RNA from the KO mice were three-fold higher than those of control Gpr151 wild type mRNA at 1 day after injury and sustained for 3 days after the injury, indicating that the KO mice were still able to express UTR of Gpr151 and more immediately responding to injury than control (Figure 2B).

Next, the regenerative capacity was monitored by in vivo axon regeneration assays using anti-SCG10 antibody ${ }^{35,36}$, showing that the $\mathrm{KO}$ mice exhibited enhanced axon regeneration after sciatic nerve injury compared to the control mice (Figures 2C, 2D, and 2E). To determine whether this enhancement is due to a neuronal effect, the regenerative potential of the cultured DRG neurons from the control and $\mathrm{KO}$ mice was monitored under a pre-conditioning injury paradigm. Without a pre-conditioning injury (-Injury), the DRG neurons cultured from both the control and KO mice did not project their axons efficiently (Figure 2F). However, a pre-conditioning injury (+Injury) strongly promoted axon regeneration. Notably, the DRG neurons from the KO mice regenerated much longer axons than those from the control mice as seen from in vivo sciatic nerve regeneration (Figures $2 \mathrm{~F}, 2 \mathrm{G}$ and $2 \mathrm{H}$ ). The number of DRG neurons of $\mathrm{KO}$ mice with an axon length shorter than $100 \mu \mathrm{m}$ was less than $50 \%$ of that of the control mice, while the KO mice had two-fold more neurons with axons longer than $300 \mu \mathrm{m}$ compared to the control (Figure 2I).

These results showed that Gpr151 protein is not required for efficient axonal regrowth after injury. Instead, neurons from the protein-null mutant mice could project their axons more robustly, hypothetically suggesting that the negative function of the Gpr151 protein in axon regeneration. It is also possible that the $\mathrm{KO}$ mice displayed a more potent regenerative capacity because of the more immediate upregulation of Gpr151-UTR-LacZ compared to the normal 
155 Gpr151 mRNA from the control mice 1 day after the injury (Figure 2B). Gpr151 is an injury156 responsive gene that has no function of its protein for regeneration. 
A

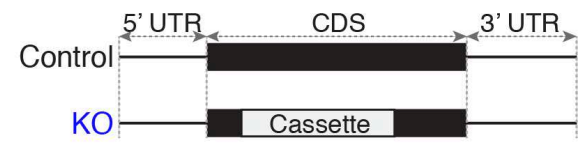

C
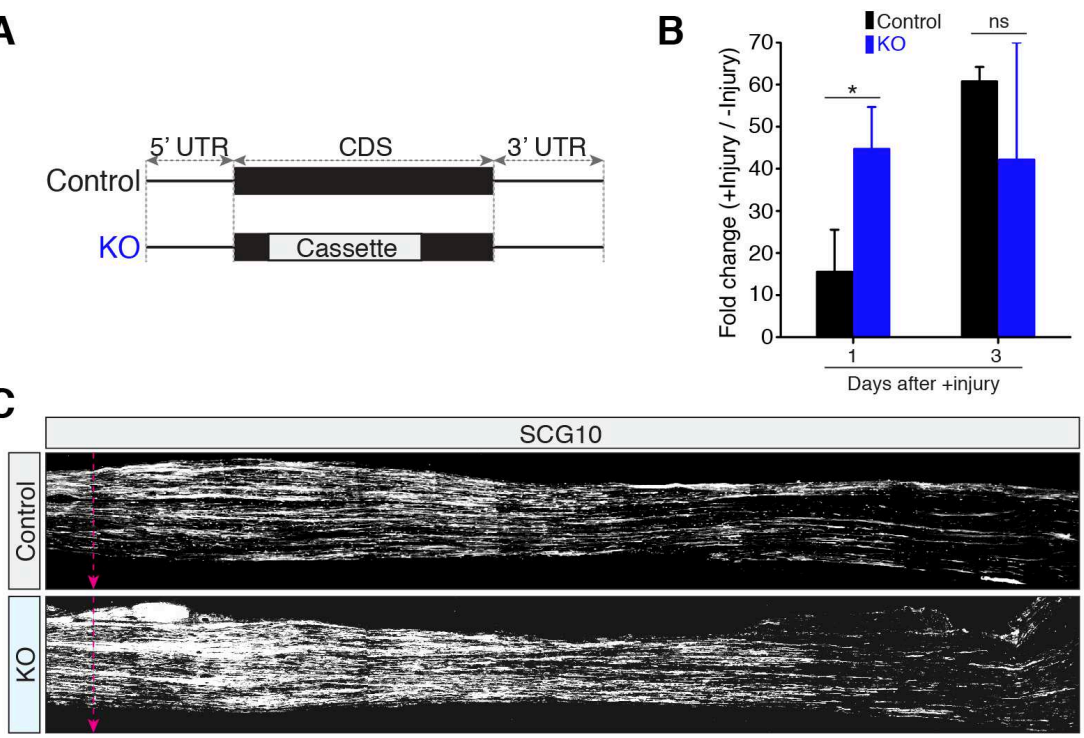

D
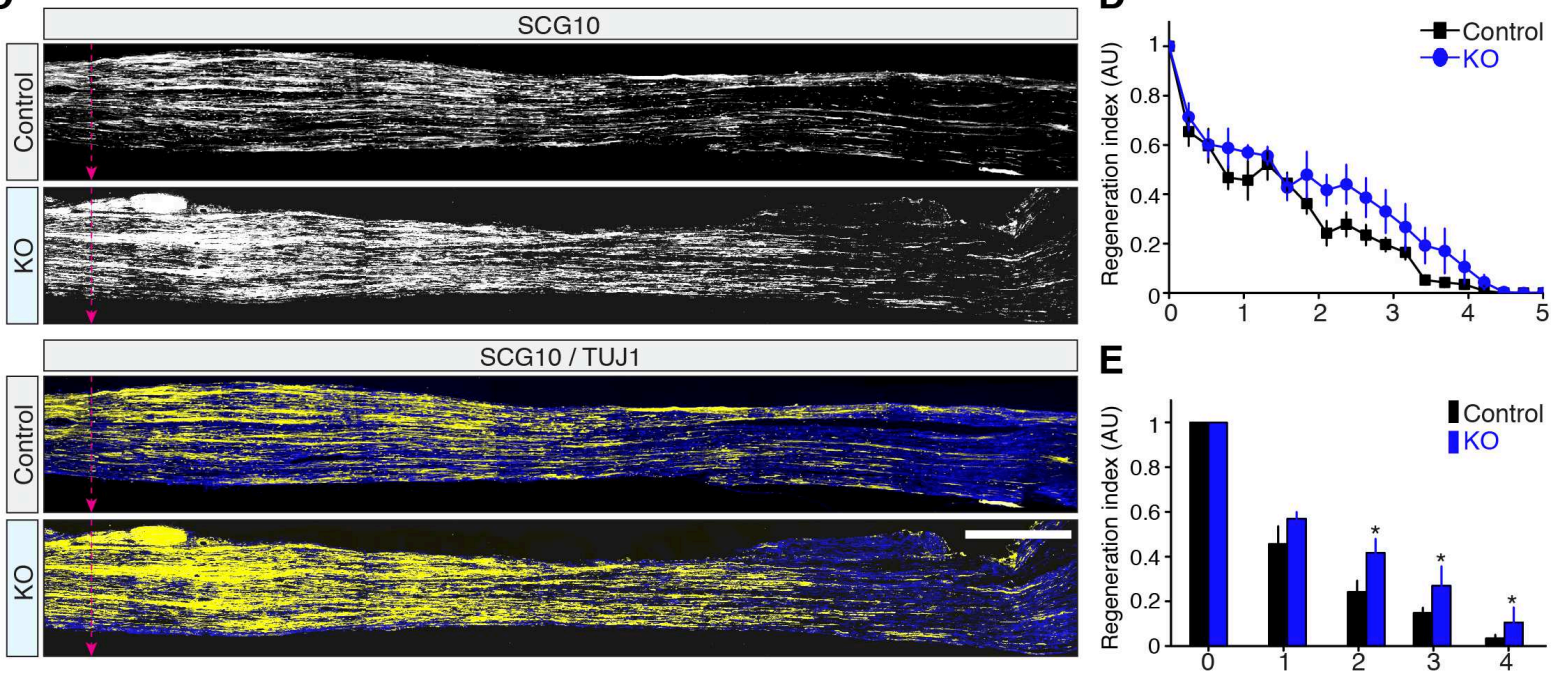

F

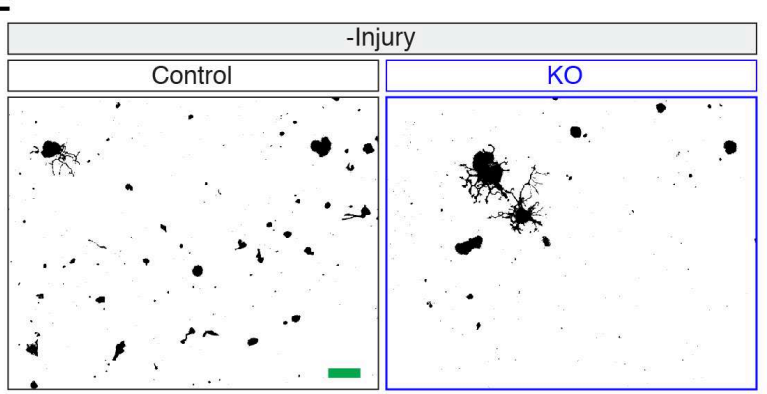

G

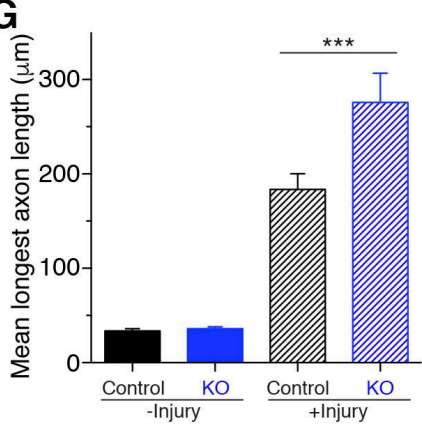

H

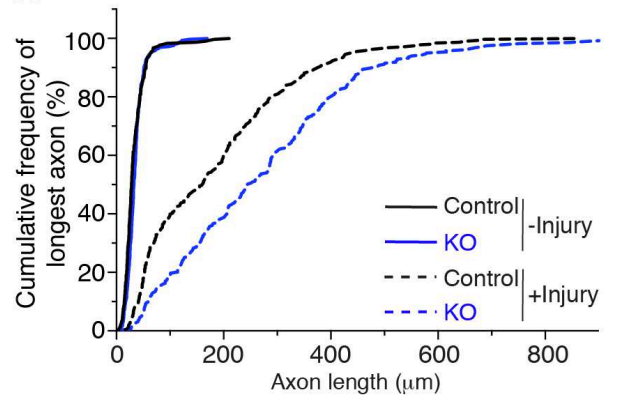

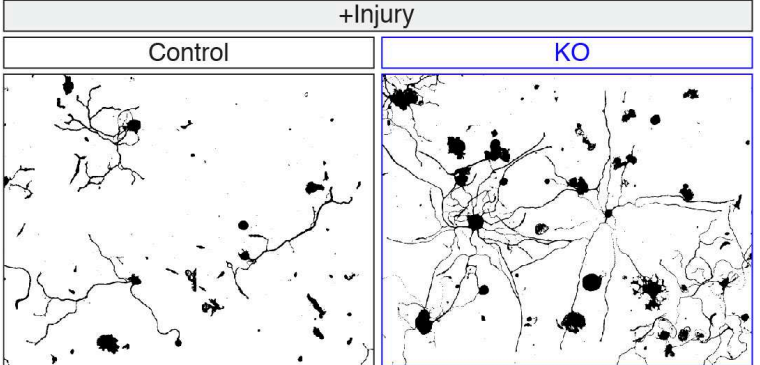

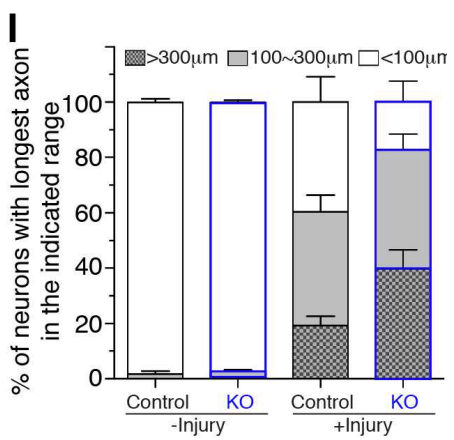

Figure 2. Gpr151 protein-null mice have no impairment of axon regeneration. (A) Schematic diagram of Gpr151 gene in control or targeted knockout (KO) mice. (B) Average fold changes of control or mutant Gpr151 mRNA levels at 1 or 3 days after sciatic nerve axotomy ( $\mathrm{n}=3$ for each; 
${ }^{*} p<0.05$, ns, not significant, ANOVA followed by Tukey tests). (C) In vivo axon regeneration assay.

165 Sciatic nerves from control or Gpr151 protein-null mice (KO) were crushed and dissected at 3 days

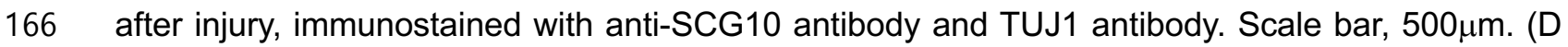

167 and E) Regeneration index from (C) ( $n=7$ for control and $n=5$ for KO; ${ }^{*} p<0.05$ by t-test; mean $\left.\pm S E M\right)$.

168 (F) Adult DRG neurons cultured to monitor neuronal pre-conditioning effect. Mouse L4-5 DRG

169 tissues were dissected at 3 days after sciatic nerve axotomy (+Injury) and plated. Scale bar, $100 \mu \mathrm{m}$.

170 (G) Average of the longest axon length from (F) (three mice for each condition, 304, 313, 291, 283

171 cells for each condition; ${ }^{* * *} p<0.001$ by ANOVA followed by Tukey tests). (H) Cumulative frequency

172 of the longest axon length from (F). (I) Percentage of neurons in three categories of the longest

173 axon length. 
Because Gpr151 KO mice still express a part of Gpr151 mRNA including 5'UTR sequence with no impairment of axon regeneration, we investigate the role of Gpr151 mRNA not its protein for axon regeneration. First, the requirement of its mRNA was monitored by knocking down Gpr151 mRNA in cultured embryonic DRG neurons and axonal regrowth was assessed. We found that knocking down Gpr151 significantly reduced neurite regrowth (Figures 3A and 3D), showing that Gpr151 mRNA is required for efficient axon regeneration. Next, two types of Gpr151 constructs were designed to investigate the role of mRNA or protein independently; CDSw, in which the 5'UTR was followed by the protein-coding region (CDS) of Gpr151; and CDSm, which was the same as CDSw except for a mutation of the start codon from AUG to AUC (Figure 3B). Western blot analysis showed that the CDSm construct was inefficient in terms of producing Gpr151 protein in the DRG neurons (Figure 3C). These were overexpressed in the DRG neurons in combination with the shRNA targeting endogenous Gpr151 mRNA to monitor their ability to restore the regenerative potential. First, CDSw overexpression failed to recover the regenerative potential when the endogenous Gpr151 was knocked down. In contrast, overexpressing CDSm successfully restored the axon regenerative capacity (Figures $3 \mathrm{~A}$ and $3 \mathrm{E}$ ). These results suggest that Gpr151 mRNA and its protein regulates axon regeneration in different ways. monitor their ability to alter the regenerative potential (Figure 3F). The over-production of Gpr151 protein via CDS not only fail to enhance axon regeneration but actually inhibited regeneration (Figures $3 \mathrm{~F}$ and 3G). However, overexpressing only the 5'UTR mRNA of Gpr151 promoted the regenerative potential, indicating that the 5'UTR is sufficient for promoting regeneration and responsible for the non-coding functions of Gpr151 that are required for regeneration. (Figures 3A, 3D, 3F, and 3G). These results show that Gpr151 is required for regeneration, functioning through its 5'UTR, while the overproduction 
A
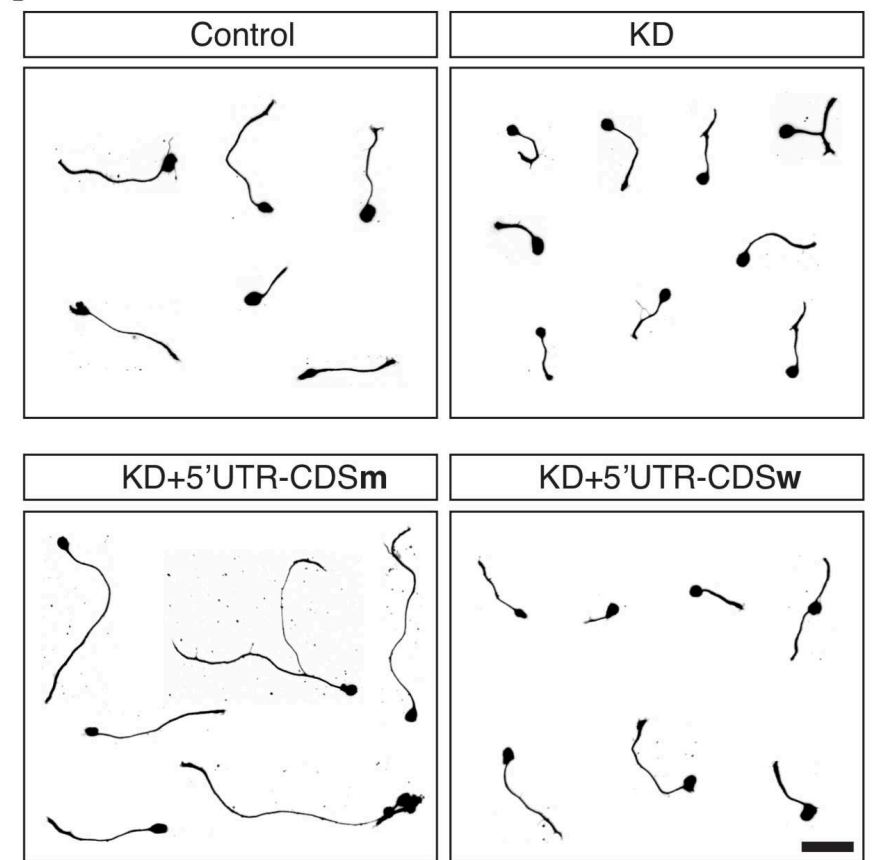

$\mathbf{F}$
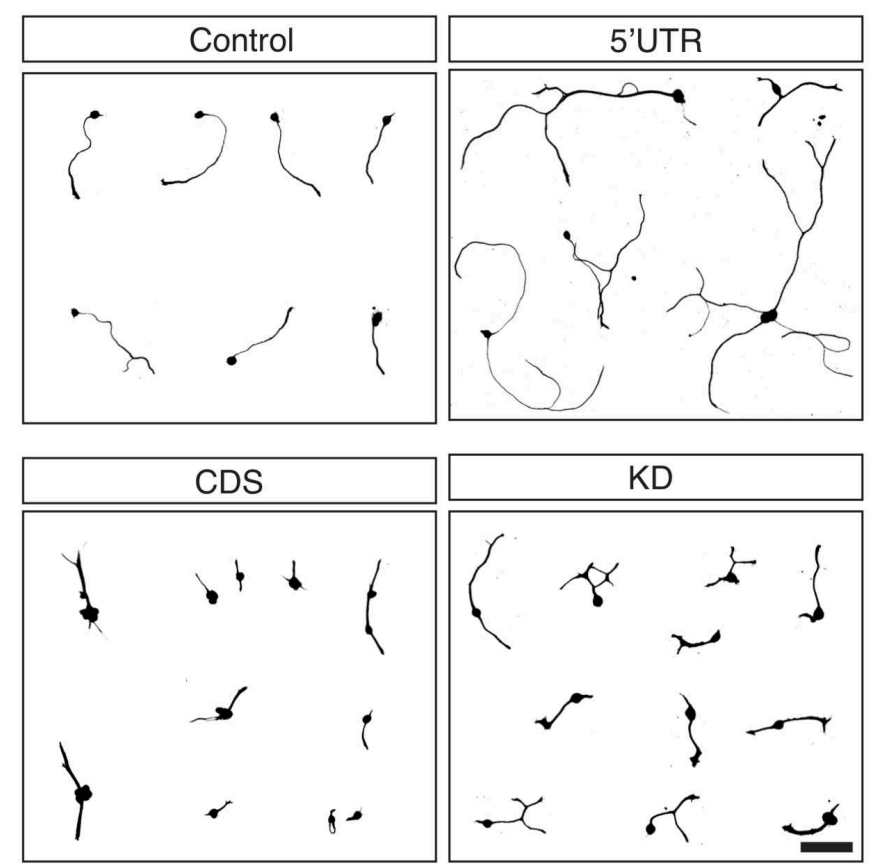

200

201

202

Figure 3. Gpr151 mRNA is required for axon regeneration, while its protein inhibits axonal
B

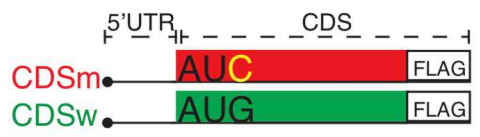

C
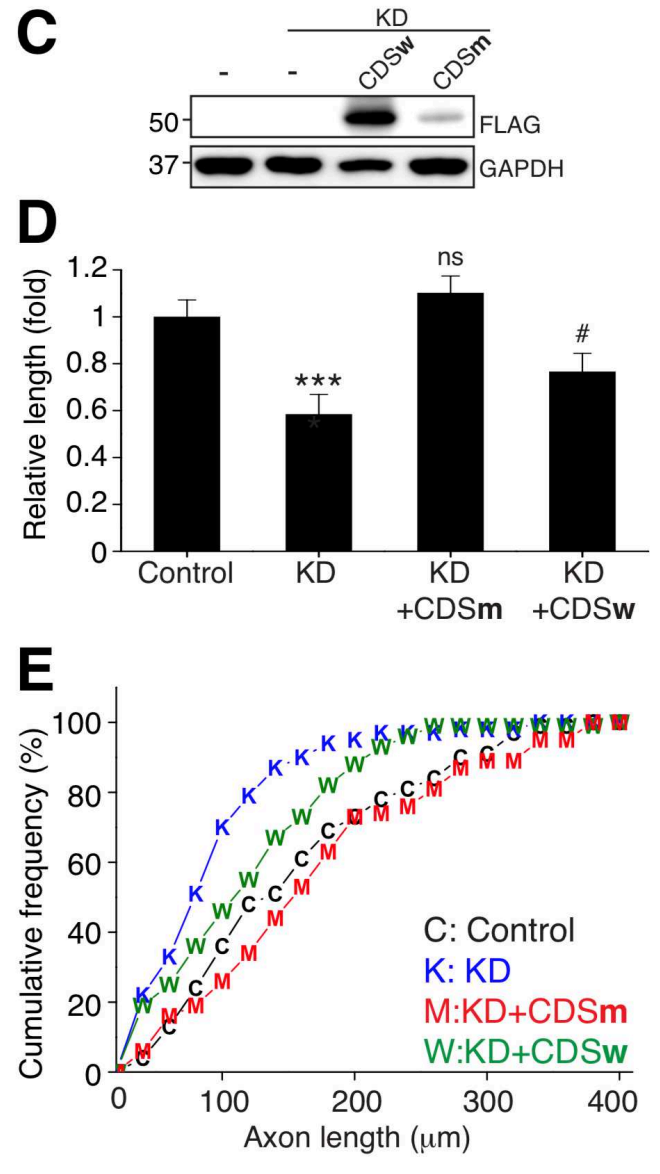

G

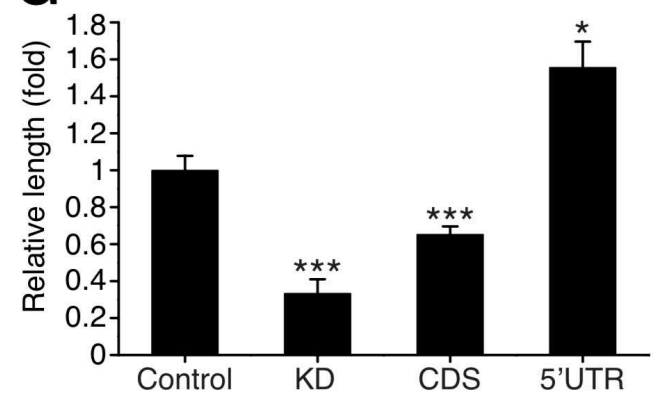

growth. (A) In vitro axon regeneration assay of embryonic DRG neurons. Control, Gpr151knockdown (KD), Gpr151-knockdown (KD) with Gpr151-5'UTR-AUC mutant overexpression 


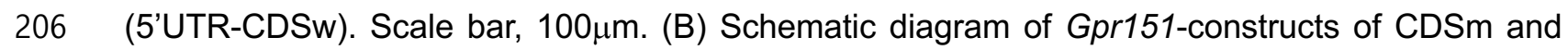
207 CDSw. AUC and AUG indicate the start codon of protein-coding sequence (CDS). 5'UTR indicates 208 5'-untranslated region of Gpr151 gene. (C) Western blot analysis validating overexpression level 209 of the constructs CDSm and CDSw shown in (B). Anti-FLAG epitope antibody was used for western 210 blot analysis. (D) Statistical analysis of (A). Average of relative axonal length $(n=67,63,67,62$ for 211 each condition; ${ }^{* * *} p<0.001,{ }^{*} p=0.05$ by ANOVA followed by Tukey tests). (E) Cumulative frequency 212 of (A). (F) In vitro axon regeneration assay of embryonic DRG neurons. Control, 5'UTR of Gpr151 213 overexpression (5'UTR), protein-coding sequence overexpression (CDS), and Gpr151-knockdown $214(K D)$. (G) Statistical analysis of $(F)$. Average of relative axonal length $(n=160,147,267,161$ cells 215 for each condition; ${ }^{*} p<0.05,{ }^{* * *} p<0.001$ by ANOVA followed by Tukey tests). 
To understand the molecular mechanisms underlying the role of Gpr151-5'UTR, RNA pulldown assays and mass spectrophotometry analysis were conducted to identify the 5'UTR of Gpr151 mRNA-interacting proteins. A total of 25 proteins were identified with high confidence scores and matched masses (Figure 4A and Supplementary information 1). Among them, we determined to investigate the involvement of CSDE1 because of its known neuronal roles. First, CSDE1 is a negative regulator of neural differentiation in human stem cells because loss of CSDE1 accelerates neurogenesis ${ }^{37}$. Second, likely gene-disrupting variants in CSDE1 are associated with autism spectrum disorder ${ }^{38}$. Interestingly, it was reported that CSDE1 knockdown promotes neurite and axon outgrowth ${ }^{38}$. These results stimulated us to hypothesize that CSDE1 is a key target of Gpr151 mRNA for its non-coding function through non-ribosomal RBPs. Furthermore, we found the existence of the CSDE1-binding motif sequences that are evolutionary conserved among the 5'UTR of mouse, rat and human GPR151 mRNA at upstream of start codon ${ }^{37,39,40}$ (Figure 4B).

The interaction between the 5'UTR and CSDE1 was confirmed by RNA pull-down assays using biotinylated 5'UTR as a bait, followed by western blot analysis using an anti-CSDE1 antibody (Figure 4C). The interaction was reversely verified using immunoprecipitation of CSDE1 in DRG tissue lysates. CSDE1 was immunoprecipitated and subjected to RT-qPCR analysis for Gpr151 to confirm that Gpr151 mRNA upregulated by nerve injury was strongly associated with CSDE1 (Figure 4D). The sharp increase in the CSDE1-associated Gpr151 mRNA shows a clear contrast to its affinity to ribosome complexes, which was unchanged after injury (Figure 1). To determine if the CAAGAA sequence in the 5'UTR was responsible for the interaction with CSDE1, a CAAGAAdeleted mutant ( $\triangle \mathrm{CSDE} 1)$ and artificial 32-mer RNA with only a 4X-repeated A-CAAGAA-G sequence (4X) was subjected to RNA pull-down assays (Figure 4E). The following western blot analysis showed that the artificial RNA 4X had a stable association with CSDE1, whereas the interaction of $\triangle \mathrm{CSDE} 1$ was significantly destabilized (Figure 4F). Human GPR151 mRNA also has the CSDE1-binding motif in the 5'UTR, and the interaction between CSDE1 and the 5'UTR of GPR151 was also confirmed (Figure 4G). These results indicated that the CAAGAA sequence in the 5'UTR of Gpr151 is primarily responsible for binding to CSDE1. 
Although CSDE1 is known to function in neurons ${ }^{37,38}$, there is no evidence showing that CSDE1 plays a role in axon regeneration. Therefore, we investigate the role of CSDE1 in an axon injury model by in vitro axon regeneration assays from embryonic DRG neurons. We found that the regenerative potential of the neurons was promoted by around $50 \%$ when CSDE1 was knocked down (Figures 4H and 4I). The RBP KHDRBS1 that was also identified as a binding protein of Gpr151-5'UTR was also knocked down for testing its involvement in axon regeneration but had no effect on axon regeneration, supporting a specific function of CSDE1. This suggests that CSDE1 has a potential function as a negative regulator of axon regeneration, implying that the 5'UTR of Gpr151 might interact to modulate the function of CSDE1 in regeneration.

CSDE1 is known to bind to single-stranded RNA, regulating mRNA translation ${ }^{41,42}$. The prediction of the RNA secondary structure of the 5'UTR indicated that the CSDE1-binding motif in the 5'UTR of Gpr151 is partially single-stranded (colored letters in 5'UTRwt, Figure 4J). To explore the possibilities for manipulating the 5'UTR-CSDE1 interaction and engineering the 5'UTR for potential applications, we generated three mutant 5'UTR forms: 1) h, the shortest 11-mer RNA without a CSDE1-binding motif; 2) 5'UTRm, the full 5'UTR sequence but with the AGCUU at the 5 bp substituted with the complementary sequence UCGAA so that the binding motif CAAGAA became fully single-stranded; and 3) $\Delta$, the 5'-part of the 5'UTR including the CSDE1-binding motif but no stem-loop region (Figure $4 \mathrm{~J}$ ). We found that $\mathrm{h}$ did not bind to CSDE1, confirming the previous results obtained using $\Delta$ CSDE1 (Figure 4F). However, 5'UTRm and $\Delta$ both displayed a more stable association than did 5'UTRWT (Figure 4K), suggesting that the CAAGAA sequence in the 5'UTR is required for its association with CSDE1 and that the interaction is stabilized when CAAGAA is single-stranded. Following this, $\Delta$ was used as a molecular competitor for baitcompetition pull-down assays (Figures $4 \mathrm{~L}$ and $4 \mathrm{M}$ ). The competition assays revealed that the interaction between the 5'UTR and CSDE1 was impaired when the concentration of the competitor was increased for both mouse Gpr151 and human GPR151 (Figures 4L and 4M). Overall, our biochemical analysis confirmed that CSDE1 is the biological interactor for Gpr151 mRNA and that the 5'UTR of Gpr151 mRNA is responsible for this interaction. 


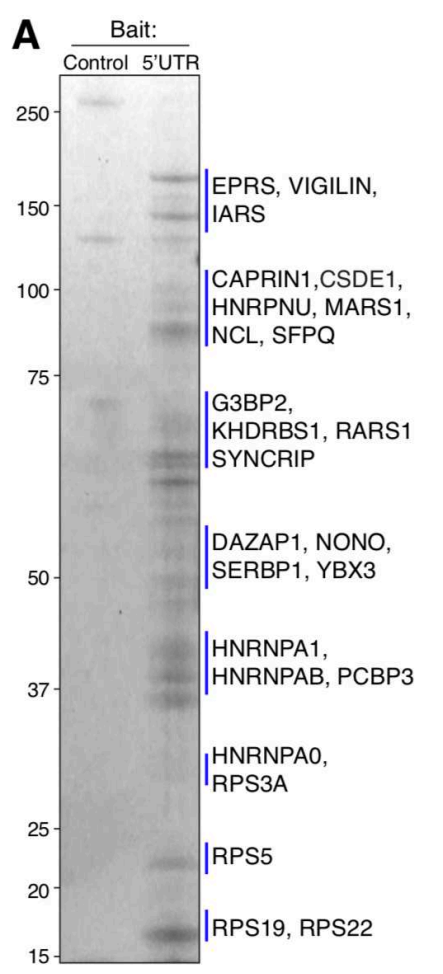

\section{B}

Mouse CCAACCTAAACÁÄÄGCTACCATCTGCAGGGAGG-----AGCTTGATG Rat ACCAACCTAATAAGAAGCTAACATCTGCAGGGAGG-----AGCTGGATG Human CAAACCTAAATAAGAATCTAACTTCTGTAAGAAGCTGTGAAGAGTGATG

C

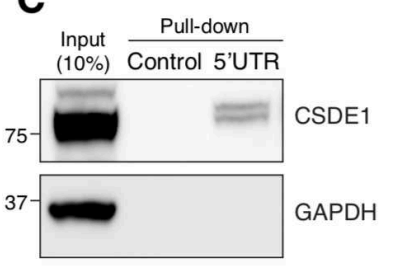

E 5'UTRWT CAAGAA 4X ACAAGAAGACAAGAAGACAAGAAGACAAGAAG

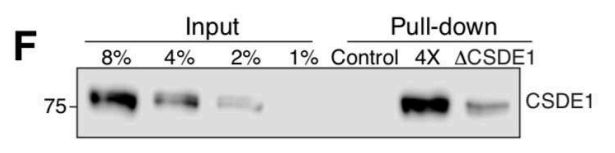

D

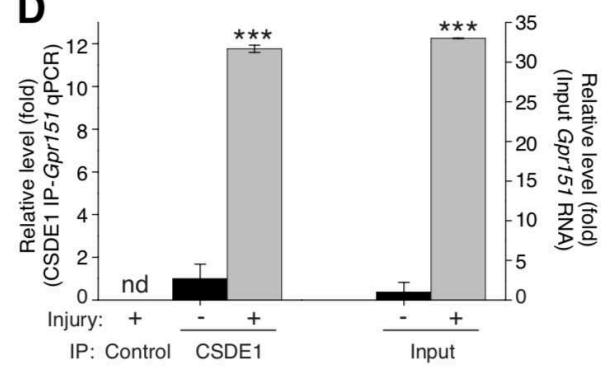

G

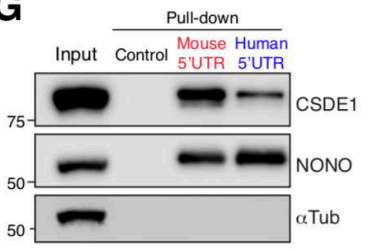

H
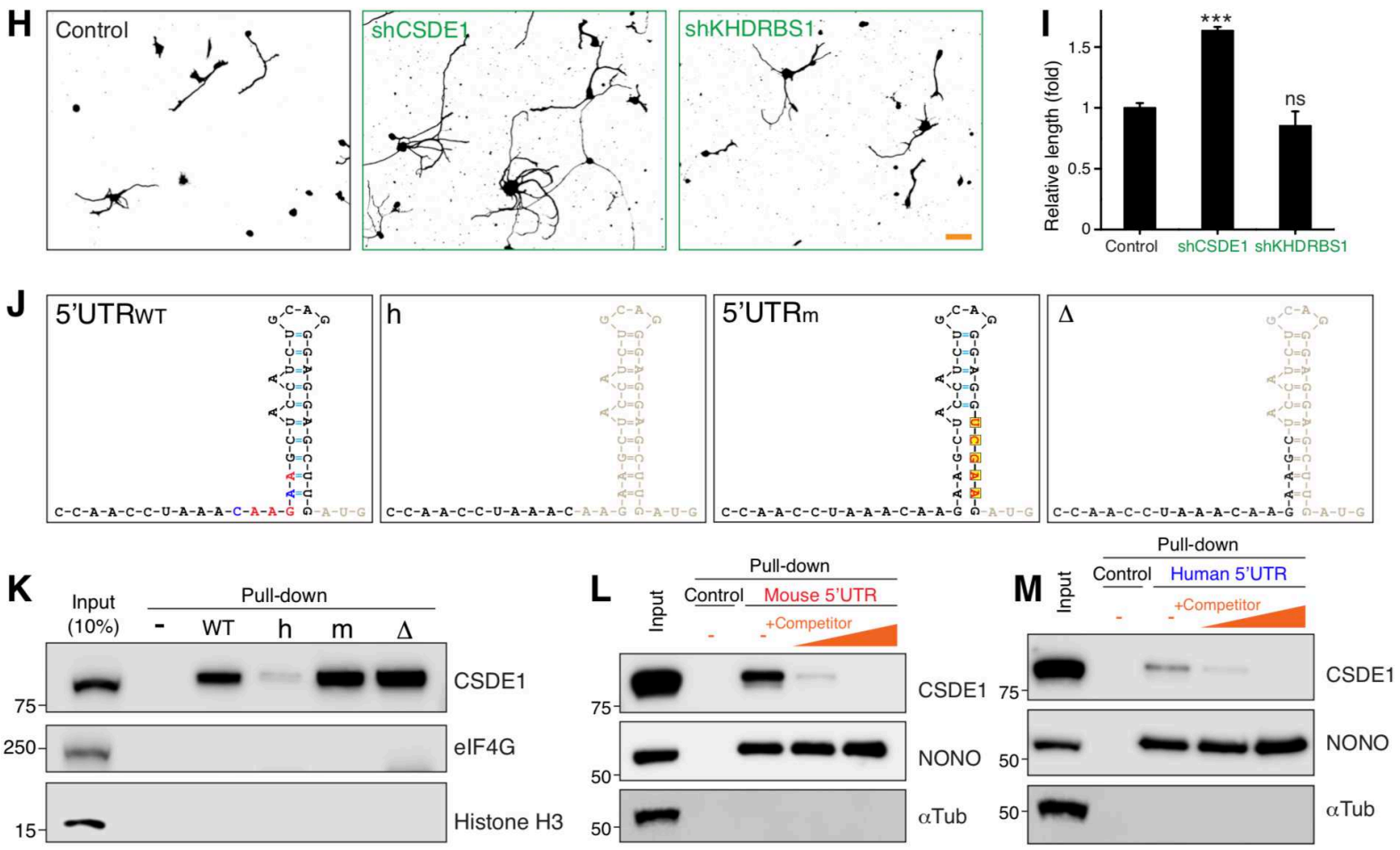

Figure 4. CSDE1 is a negative regulator of axon regeneration interacting with 5'UTR of

277 Gpr151 mRNA. (A) Coomassie staining of SDS-PAGE of 5'UTR-binding proteins. (B) Alignment of 5'UTR sequences of mouse, rat and human GPR151 gene. Green box, nAAGnA, CSDE1binding consensus motif, yellow shadow, the start codon of Gpr151 CDS. (C) Western blot analysis 
of 5'UTR pull-down assay. (D) Relative folds of Gpr151 mRNA levels analyzed by RT-qPCR ( $n=3$, ${ }^{* * *} p<0.001$, nd, not determined by t-test; mean $\pm S E M$ ). (E) Illustration of the artificial RNA sequences of $\triangle \mathrm{CSDE} 1$ or $4 \mathrm{X}$ mutant. (F) Western blot analysis of pull-down assay with the baits, $\triangle \mathrm{CSDE} 1$ or $4 \mathrm{X}$ mutant. (G) Western blot analysis of pull-down assay with the baits, mouse 5'UTR or human 5'UTR of GPR151. (H) In vitro axon regeneration assay from control, CSDE1 knockdown (shCSDE1) and KHDRBS1 knockdown (shKHDRBS1) embryonic DRG neurons. Scale bar, $100 \mu \mathrm{m}$. (I) Statistical analysis of regenerating axon length of $(H)(n=254,198,167$ for control, shCSDE1 and shKHDRBS1; ${ }^{* *} \mathrm{p}<0.001$, ns, not significant by ANOVA followed by Tukey tests; mean \pm SEM). (J) Illustrations of the secondary structures of 5'UTR of Gpr151 wild type (5'UTRWT), no CSDE1-binding motif $(\mathrm{h})$, single-stranded CSDE1-binding motif (5'UTRm) and no stem $(\Delta)$ mutant. (K) Western blot analysis of pull-down assay with the baits of $(\mathrm{J})$. ( $\mathrm{L}$ and $\mathrm{M})$ Western blot analysis of pull-down assay with the competitor $\Delta$ for mouse and human 5'UTR. 
5'UTR of Gpr151 modulates the CSDE1-associated RNA pool to promote axon regeneration

Because CSDE1 functions as a negative regulator of axon regeneration in vitro (Figures 4H and 4I), we next tested whether this function is modulated by its interaction with the Gpr151-5'UTR. First, we compared the regenerative potential of 5'UTRwT and 5'UTRm-overexpressing neurons to determine whether the enhanced CSDE1-binding affinity of 5'UTRm affects its ability to promote axon regeneration. We found that $5^{\prime} \mathrm{UTR}_{\mathrm{WT}}$ promoted axon regeneration by up to $50 \%$ compared to the control (Figures $5 \mathrm{~A}$ and $5 \mathrm{~B}$ ), consistent with the results of the initial assay (Figure $2 \mathrm{G}$ ). However, 5'UTRm expression led to significantly more robust regeneration than did 5'UTRWT expression (Figures $5 \mathrm{~A}$ and $5 \mathrm{~B}$ ). To verify that the enhanced function of 5 'UTRm requires the association with CSDE1, an additional mutation deleting the CSDE1-binding motif was introduced to 5'UTRm (5'UTRm $\triangle \mathrm{CSDE} 1$ ) and was tested for its effect on regeneration. We found that the mutant 5'UTRm $\triangle$ CSDE1 did not promote axon regeneration as much as 5'UTRWT did (Supplementary figure 3), suggesting that the function of $5^{\prime}$ UTR in regeneration is dependent on its physical association with CSDE1.

As 5'UTRm effectively enhances axon regeneration, we used the mutant 5'UTRm for studying the mechanisms involved in the regulation of CSDE1 by 5'UTR. Based on the known role of CSDE1 as an RBP regulating the interacting mRNA, we hypothesized that 5'UTRm, by binding to CSDE1, may induce dissociation of the interacting mRNA and inhibit the function of CSDE1. We developed a comparative analysis for 5'UTR-induced changes in CSDE1-associated mRNA, one similar to the initial analysis for Rp/22-HA IP-seq in Figure 1B, and also assessed 5'UTRmdependent DEGs to control for the mRNA levels. Notably, a group of mRNAs ( $19.0 \%$ of total) exhibited significant changes in their binding behavior with CSDE1 following 5'UTRm overexpression without corresponding changes in their expression levels $\left(78.6 \%,-1<\log _{2}[\right.$ Fold change] < 1). A large number among these mRNA (16.9\% of total) were dissociated from CSDE1, while a smaller group (2.7\%) formed a more stable association (Figure 5C and Supplementary information S2). Meanwhile, the majority of the mRNAs $(80.4 \%)$ did not demonstrate dramatic changes in their interaction with CSDE1, even when they were differentially expressed $(8.4 \%)$. Additionally, there were DEGs with mRNA that was up- $(11.6 \%)$ or downregulated $(9.9 \%)$ over 
320 two-fold (Figure 5C). The comparative analysis revealed that 5'UTRm overexpression regulated 321 the pool of CSDE1-associated coding mRNAs, suggesting that the dissociation of these mRNA is responsible for the CSDE1-dependent function of Gpr151-5'UTR. These results suggest that regulation of RBP function and its interaction with target mRNA can be important molecular mechanisms when an mRNA appears to have a non-coding function via interaction with a specific RBP.

Because the biological outcome of 5'UTRm is an improvement in the regenerative potential under an axon injury paradigm, we investigated the biological functions of the mRNAs that are released from CSDE1 after 5'UTRm overexpression. DAVID tools were utilized for gene ontology and signaling pathway analysis ${ }^{11,43-45}$. it was found that the known functions of the identified genes were specifically related to regulating protein localization and transport, while cytoskeletal remodeling, apoptosis, cell growth, and behavioral control functions were also enriched (Figure 5D and supplementary information S3). In addition, pathway analysis revealed that genes related to ribosomes and ribosome synthesis made up a significant proportion of the group of genes observed to be released from CSDE1 after 5'UTRm overexpression (Figure 5E and Supplementary information S4). Genes related to neurodegenerative disorders such as Alzheimer's disease, Huntington's disease, Parkinson's disease, and amyotrophic lateral sclerosis and to neurotrophin signaling or axon guidance were also enriched among the genes dissociated from CSDE1 (Figure 5E and Supplementary information S4). This analysis shows that our unconventional experimental design investigating the CSDE1-interactome reveals the biological pathways that have not been identified in previous DEG studies related to peripheral nerve injury 8,31,46. The genes identified in these pathways also did not exhibit any significant changes in their expression levels, suggesting that a simple DEG analysis may not pick them up.

Finally, we analyzed proteomic changes in control and 5'UTRm-overexpressing neurons. Antibody-array analysis showed that $5^{\prime}$ UTRm induced the differential up- $(14.9 \%)$ or downregulation (17.4\%) of a total of 1,358 target proteins (Figure $5 \mathrm{~F}$ and Supplementary information S5). We subjected these to a comparative analysis with CSDE1 IP-seq data and found that the mRNAs encoding the target proteins exhibited distinctive changes in their CSDE1- 
348 associated conditions after 5'UTRm overexpression (Figure 5G and Supplementary information 349 S6). A group of mRNAs, including Eef1g, Fgfr2, and Scng (red-closed circles, 0.8\%), were 350 dissociated from CSDE1 when 5'UTRm was overexpressed (Figure 5G and Supplementary 351 information S6). However, a large number of mRNAs, including Ywhaz (open circles), had no 352 significant changes in their protein levels, while another group that were released from CSDE1 353 (e.g., Tshz2, Tubb3, Mta1, and Nr2f2l) experienced a reduction in their protein levels. This 354 suggests that the mRNAs released from CSDE1 have different fates in terms of their routes to 355 either ribosomes or other RBPs when promoting the regeneration of neurons. 


\section{B}

A
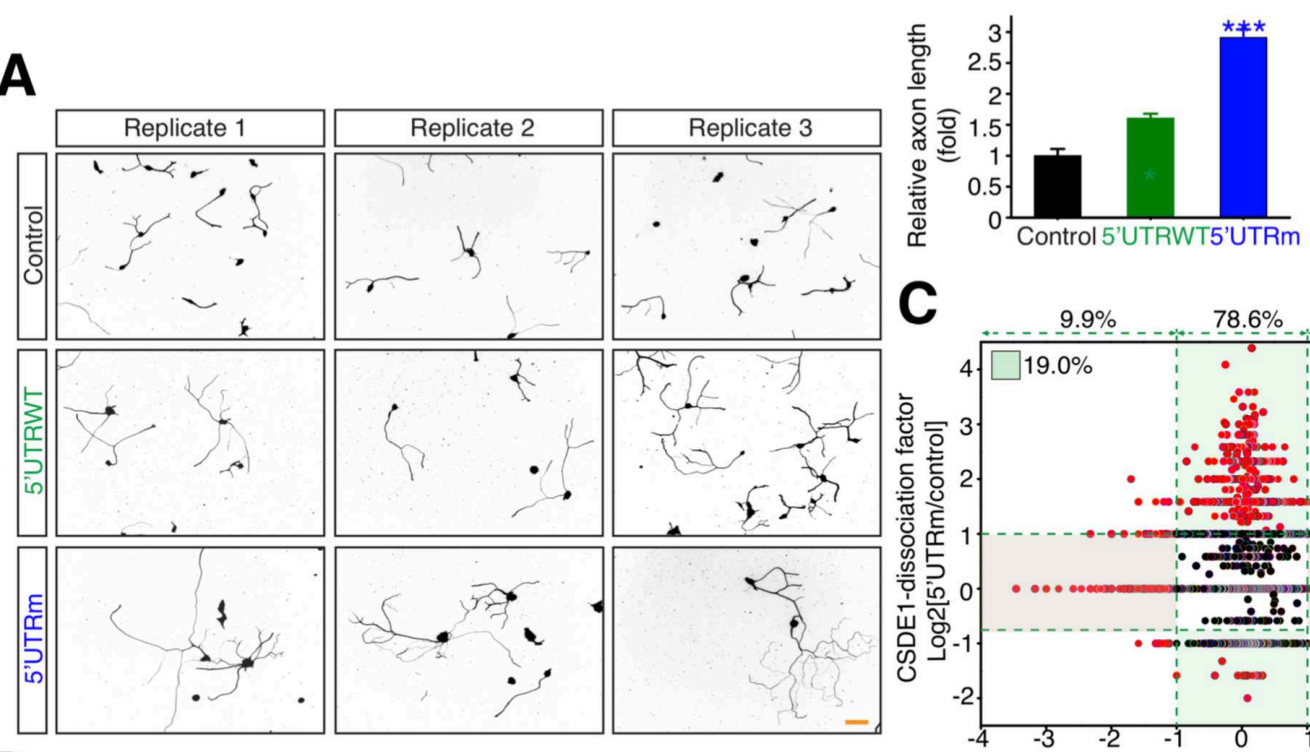

D

E
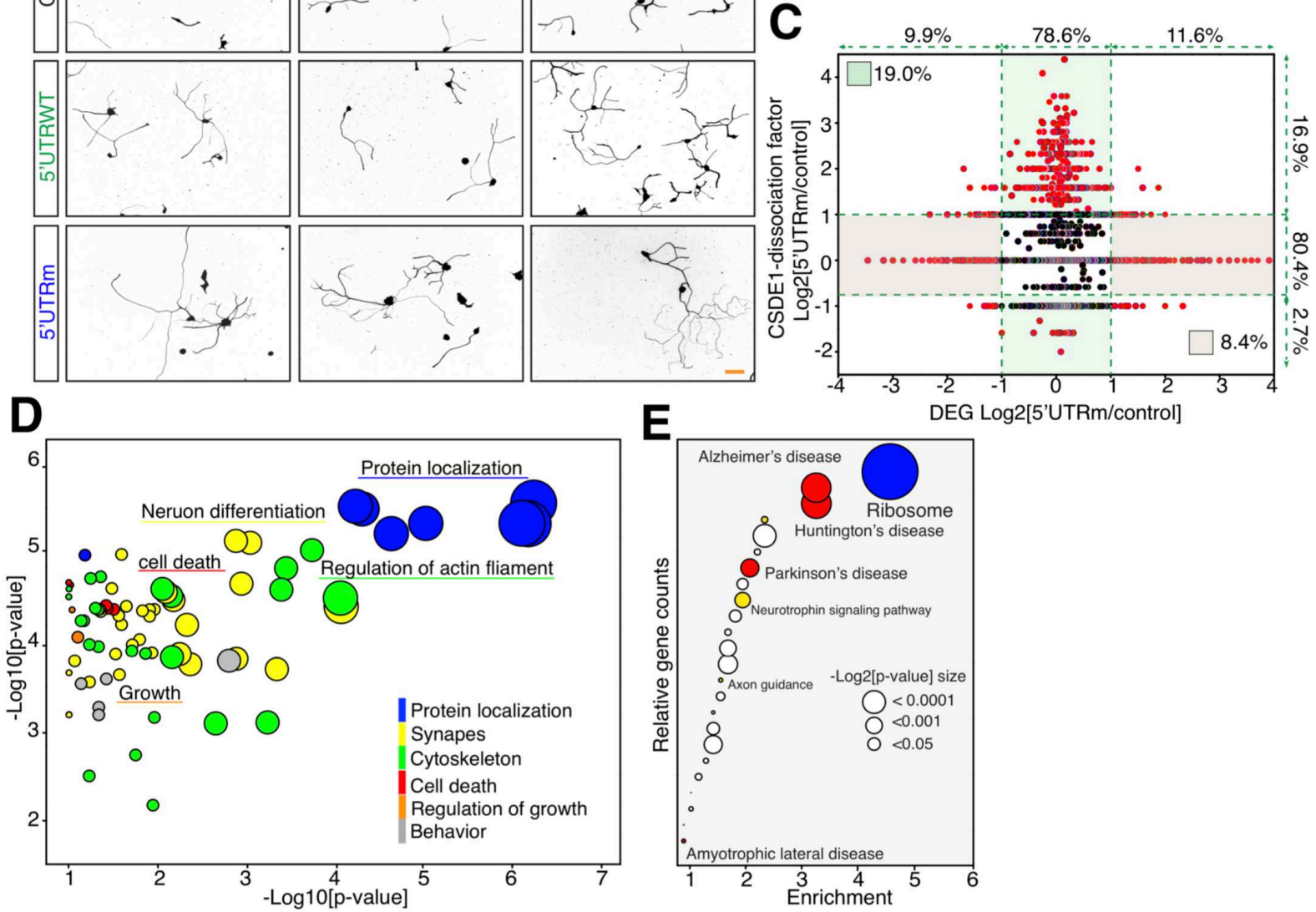

F

G
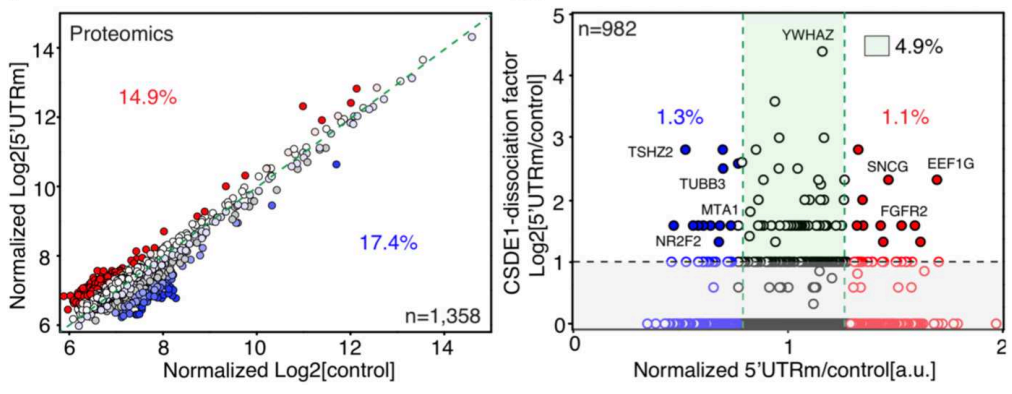

Figure 5. Expressing engineered 5'UTR of Gpr151 mRNA modulates CSDE1-RNA interaction, resulting in dissociation of an RNA group related to distinct biological processes. (A) In vitro axon regeneration assay of embryonic DRG neurons expressing control vector, 5'UTR of Gpr151 
364 (5'UTRWT) or a mutant 5'UTR with single-stranded CSDE1-binding motif (5'UTRm). Scale bar, $365100 \mu \mathrm{m}$. (B) Statistical analysis of relative average axon length from (A) $(n=97,104,98$ cells for 366 control, $5^{\prime}$ UTRWt and 5 'UTRm; ${ }^{*} p<0.05,{ }^{* * *} p<0.001$ by ANOVA followed by Tukey tests; 367 mean $\pm S E M)$. (C) Two-dimensional plot with the $x$-axis of log2-transformed fold changes of 368 [reads@5’UTRm / reads@control] and the y-axis of. See also supplementary information S2. (D 369 and E) Gene ontology analysis (D) and KEGG pathway analysis (E) of the genes dissociated from 370 CSDE1 by 5'UTRm overexpression, shown in the upper green box in (C). (F) Proteomic analysis 371 of antibody array results with the $x$-axis of normalized log2-transformed values in control and $y$ 372 axis of normalized log2-transformed values in 5'UTRm. The color red and blue indicates 373 upregulated or downregulated target protein by $30 \%$ or more, respectively. Percentages indicate 374 the relative ratios of the colored targets of total 1,358 probes. $(G)$ Target proteins in (F) are plotted 375 for the corresponding CSDE1-dissociation factor of their mRNA, negative log2-transformed fold 376 changes of CSDE1-IP [reads@5’UTRm / reads@control]. 


\section{Expression of the engineered RNA promotes axon regeneration in vivo}

To test if the engineered 5'UTR of Gpr151 is a potential tool for promoting the regenerative capacity in vivo, adeno-associated virus (AAV) expressing 5'UTRm was utilized for in vivo gene delivery in two different axon regeneration models. In PNS axon regeneration assays, mouse sciatic nerves were damaged via crush injury and dissected 3 days after the injury (Figure 6A). The sciatic nerves of 5'UTRm-expressing mice exhibited a dramatic increase in their axon regeneration as observed in the regeneration assays using cultured neurons (Figures 6B, $6 \mathrm{C}$ and 6D). Similar results were reproduced in central nervous system (CNS) axon regeneration assays with an optic nerve injury model (Figure 6F). The regenerating axons in the optic nerves were traced using cholera toxin B (CTB). We found that 5'UTRm overexpression dramatically increased the number of regenerating axons in the injured optic nerves (Figures 6F and 6G).

The neuronal injury responses in the PNS and the CNS are known to be differentially regulated, resulting in significantly inefficient axon regeneration in the CNS compared to that in the PNS (Curcio and Bradke, 2018; He and Jin, 2016; Mahar and Cavalli, 2018). Hence, to test if the marked upregulation of Gpr151 is a molecular response specific to the PNS, where regeneration is robust, qPCR for Gpr151 was performed in both systems. Gpr151 mRNA is upregulated in the DRG neurons after sciatic nerve injury, while it was not observed in the retinal tissue after optic nerve injury (Figure $6 \mathrm{H}$ ). This suggests that the PNS and the CNS may have different injuryresponsive epigenetic mechanisms regulating Gpr151 expression (Jiang et al., 2018). However, both systems produced similar outcomes in the promotion of axon regeneration when the Gpr1515'UTRm was overexpressed. Therefore, components in the downstream signal transduction regulated by 5'UTR may be available to function in both systems. 
A

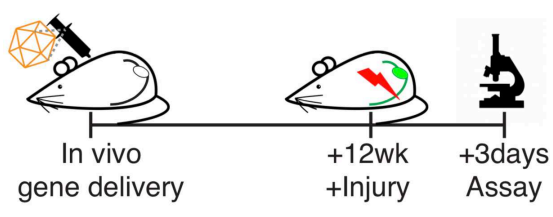

B

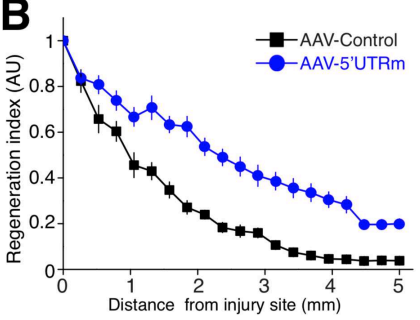

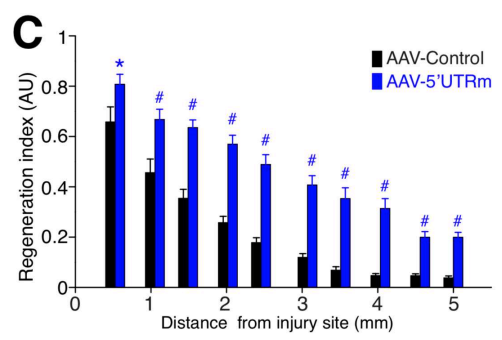

D
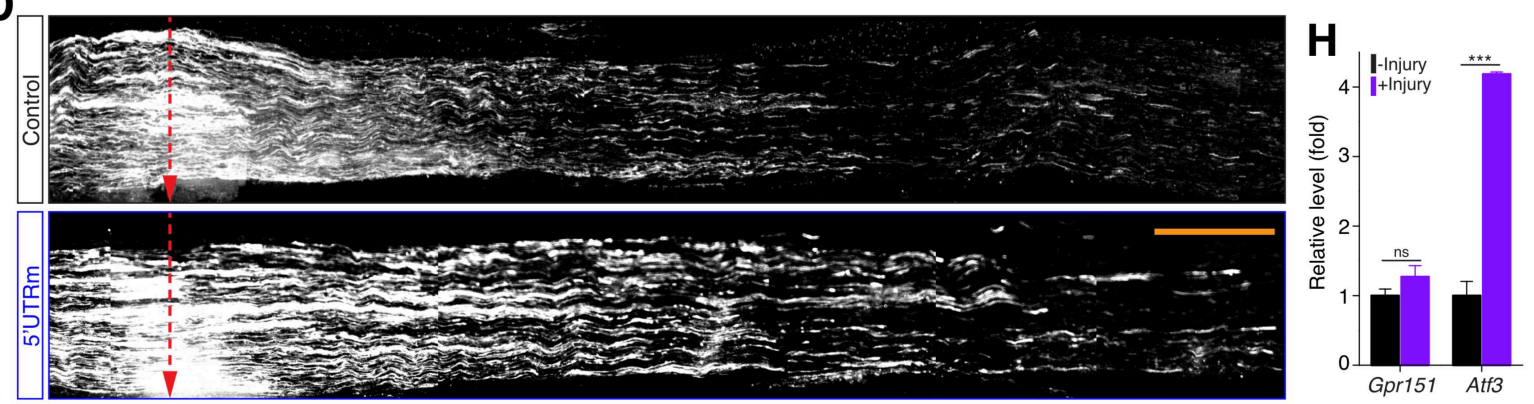

E

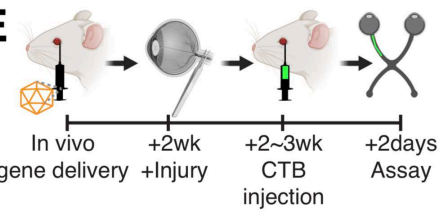

G

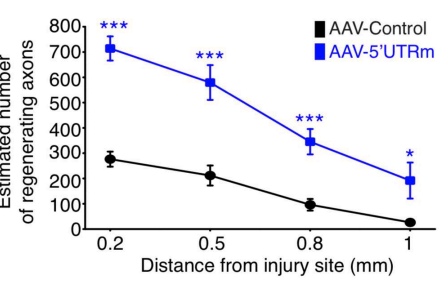

F

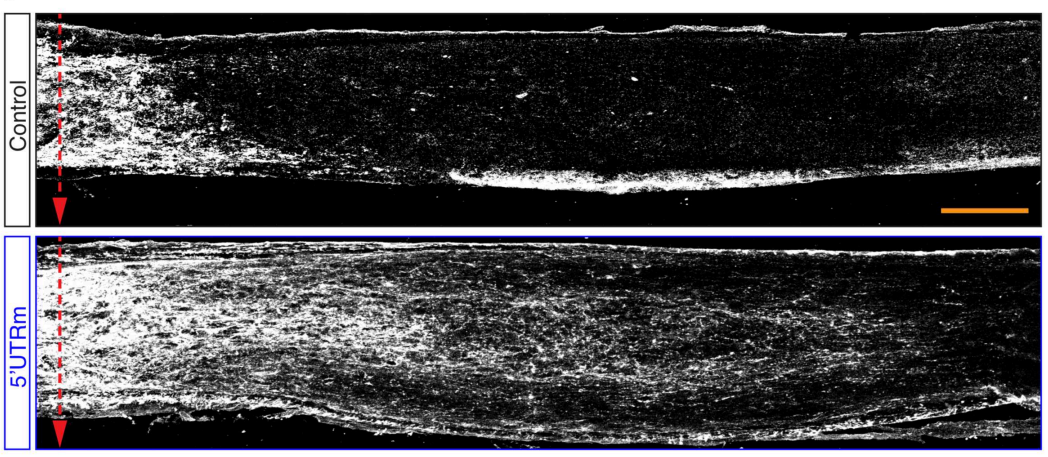

Figure 6. In vivo gene delivery of engineered 5'UTR of Gpr151 mRNA promotes axon

regeneration. (A) Experimental scheme of in vivo gene delivery for in vivo axon regeneration assay in mouse sciatic nerves (wk, week(s)). (B and C) In vivo regeneration index from (D) $(n=8$ for control, 10 for 5 'UTRm; ${ }^{*} p<0.05,{ }^{\#} p<0.001$ by t-test; mean $\left.\pm S E M\right)$.

(D) In vivo axon regeneration assay from sciatic nerves. Representative longitudinal sections of the sciatic nerves from control or 5'UTRm-expressing mice. Red dotted arrows indicate the injury site. Scale bar, $500 \mu \mathrm{m}$. (E)

Experimental scheme of in vivo gene delivery for in vivo axon regeneration assay in mouse optic nerves (wk, week(s)). (F) Representative longitudinal sections of optic nerves from control or 5'UTRm-expressing mice. Red dotted arrows indicate the injury site. Scale bar, $200 \mu \mathrm{m}$. (G)

413 Estimated numbers of regenerating axons ( $n=5$ for control, 6 for 5 'UTRm; ${ }^{*} p<0.05$, ${ }^{* * *} p<0.001$ by 
414 t-test; mean \pm SEM). (H) qPCR analysis of Gpr151 and Atf3 from mouse retina with (+Injury) or 415 without (-Injury) injury ( $\mathrm{n}=3$ for each condition; ${ }^{* * *} p<0.001$, ns, not significant by t-test; mean \pm SEM).

Retrospective analysis shows that Sox11 regulates the regenerative potential via 5'UTR

We were motivated to re-analyze our previously published injury-responsive transcriptomic data to search for additional examples of injury-induced mRNA with potential noncoding function. Dual leucine zipper kinase (DLK) is a key molecule regulating injury responses including axon regeneration and degeneration and it is required for the regenerative transcriptional program by activating a mitogen-activated protein kinase (MAPK) pathway ${ }^{49}$. Previously, we identified injury-responsive DLK-dependent transcriptome in a sciatic nerve regeneration model at different time points after injury (Shin et al., 2019a). We re-plotted these original gene expression profiles to show the relationship between DLK dependency and injury responsiveness, with the size of the circles indicating the relative fold change 72 hours after injury (Figure 7A). The individual genes are colored according to their ribosome-association efficiency as identified in the present study (Figure 1C). We found that only $21 \%$ of the 593 DLK-dependent, injury-responsive upregulated genes exhibited an increase in their ribosome-association efficiency (red circles, Figure 7A), consistent with the results shown in Figure 1C. To test the highly DLK-dependent and injury-responsive mRNA group for the potential non-coding function, we again selected singleexon genes. Jun, Sox11, and ler5 comprised the single-exon gene group with DLK-dependent upregulation after injury. Jun and Sox11 displayed increased ribosome-association after nerve injury (red circle) whereas the ribosome-association of ler5 mRNA was unchanged (gray circle) (Figure 7A). These genes were subjected to in vitro axon regeneration assays to investigate the requirements for regeneration. Of the three candidate genes, Sox11 was found to be required for axon regeneration (Figure 7B and Supplementary figure 4). Sox11 encodes a transcription factor that has been implicated in the regulation of axon regeneration ${ }^{50-52}$. We tested whether Sox 11 mRNA plays a non-coding function via its UTR, similarly to the case of Gpr151. We found that Sox11 knock-down reduced the regenerative potential, but Sox11-knockdown neurons recovered 
442 7C). These results demonstrate that Sox11 is required for axon regeneration and that the 5'UTR

443 of Sox 11 mRNA is sufficient for positively regulating the regeneration process through a non-coding

444 function. Because Sox11 mRNA became more strongly associated with ribosome complexes when

445 Sox11 mRNA was upregulated after axonal injury, Sox11 protein may also have a specific role in

446 regulating axon regeneration, independent of the non-coding function of its mRNA. Collectively,

447 our approach to investigate single-exon genes for their translation-independent mRNA function

448 uncovers an additional example of injury-induced coding and non-coding RNA (cncRNA), Sox11

$449 \mathrm{mRNA}$, that promotes axon regeneration after injury.

450 Taken together, our data demonstrate the non-coding function of Gpr151 mRNA for 451 promoting axon regeneration via the association of its 5'UTR with CSDE1 and suggest the need

452 for the separate functional tests of mRNA and its protein in DEG studies to understand the 453 mechanisms underlying cellular responses. 

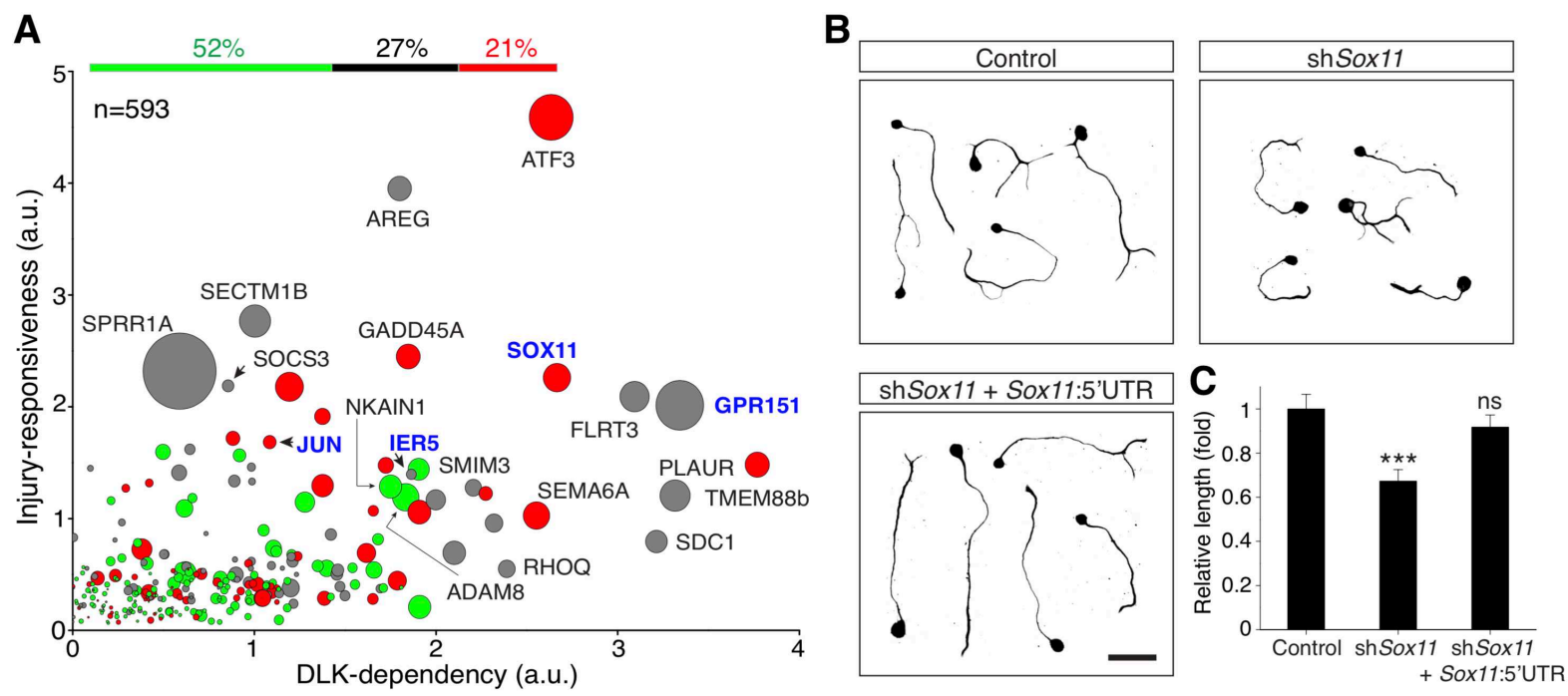

D

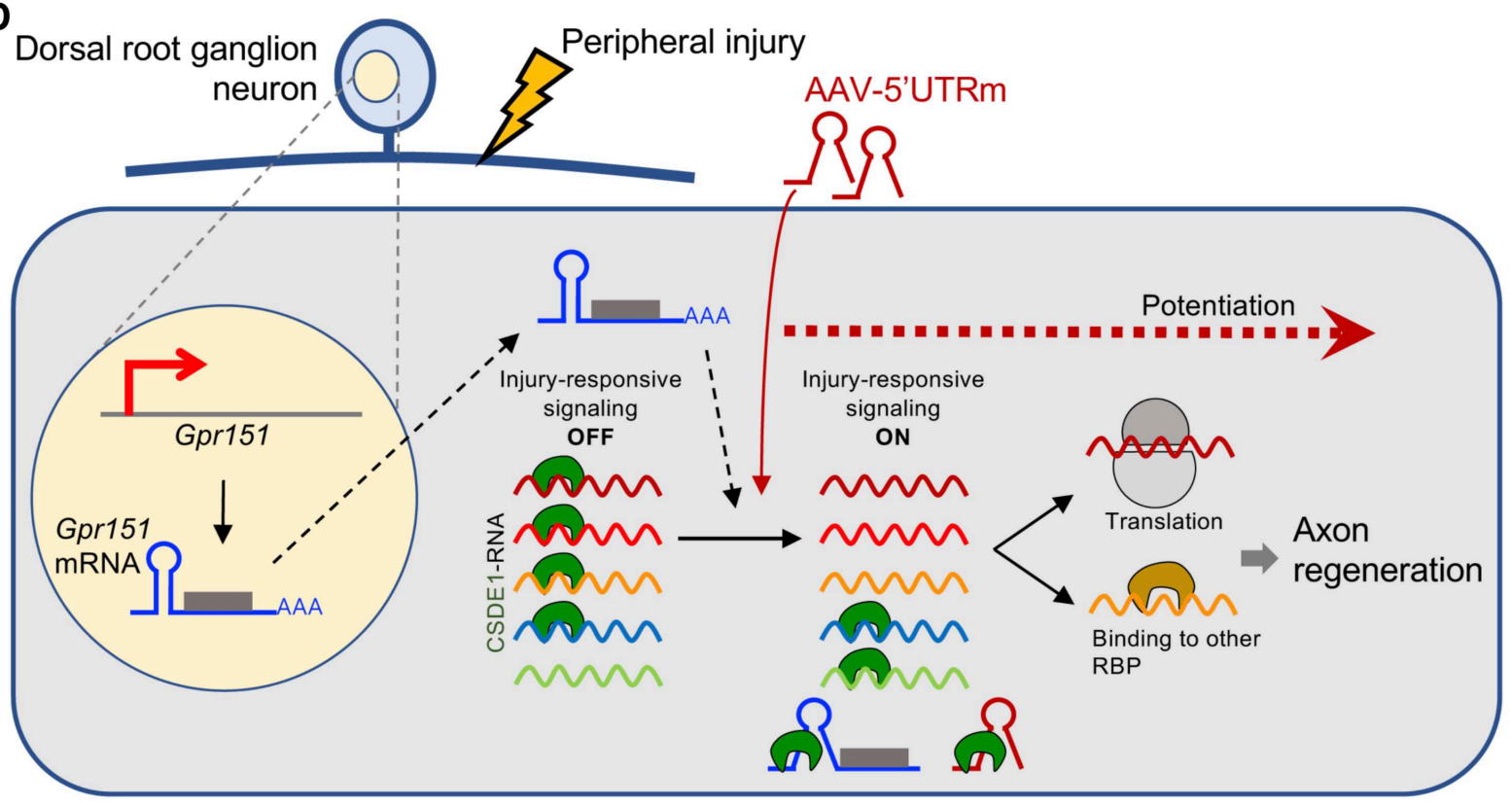

Figure 7. Retrospective re-analysis of the previously published DEG data suggests 5'UTR

of Sox11 regulates neuronal potential for axon regeneration. (A) Three-dimensional plot with

the x-axis of DLK-dependency (a.u.), the y-axis of injury-responsiveness (a.u.) and the circle sizes of the relative fold change at 72 hours after injury. The colors indicate ribosome-association efficiency; red, increased, black, not changed and green, decreased at 24 hours after injury. Total 593 genes were selected as DLK-dependent injury-responsive genes. (B) In vitro axon regeneration assay of re-plated embryonic DRG neurons. Control, Sox11 knock-down (shSox11) and Sox11 knock-down with 5'UTR of Sox11 overexpression (shSox11 + Sox11:5'UTR). Scale bar, $100 \mu \mathrm{m}$. (C) Average relative axon length of $(C)\left(n=63,86,70\right.$ cells for each; ${ }^{* * *} p<0.001$, ns, 
not significant by ANOVA followed by Tukey tests; mean \pm SEM). (D) Illustration of the proposed 469 model.

470 
Neuronal responses after injury have been investigated using various experimental tools

473 to identify important mechanisms regulating the neuron-intrinsic regeneration program $1,8,48,53$.

474 Emerging omics technologies have facilitated the gaining of new knowledge in the axonal 475 regeneration pathway ${ }^{54}$. For example, DEG analysis is often used as a method to identify genes 476 regulating the neuronal injury responses, based on the premise that significantly upregulated or downregulated genes may be functionally important for the biological process. Indeed, transcriptome studies in injured peripheral neurons have uncovered injury-responsive genes, among which a subset has been implicated in the regulation of axon regeneration. However, there still remain many injury-induced genes without clearly defined function in axonal regeneration or other injury responses. To overcome the limitation of single-omics approach and enhance selectivity for interesting features of genes, we took multi-omics combinatorial methods. There were earlier studies taking combinatorial approach comparing injury-induced proteome and transcriptome to identify signaling networks that are required for activation of the transcriptional regenerative program ${ }^{54-56}$. In the present study, we compared transcriptome and ribosomeassociation efficiency of protein-coding DEGs after sciatic nerve injury to directly address the fates of the injury-responsive mRNA. We identified a group of genes that are upregulated in response to axonal injury without changes in their ribosome-association efficiency, supporting a striking discordance between transcriptional and translational controls after injury.

Gpr151 was one of the injury-responsive genes whose dramatic upregulation after nerve injury has consistently been reported in several DEG studies ${ }^{10,25,26,30,31,34,57-59}$. Gpr151 protein is known to play a molecular role as an orphan GPCR in signaling pathways controlling addiction and pain ${ }^{24-26,28,29,60-64}$. Therefore, an easily driven hypothesis would be that the GPCR function of Gpr151 is enhanced by the increased gene expression and contributes to the regulation of the regenerative signaling after injury. However, in contrast to this notion, we found that the upregulated Gpr151 mRNA is not directed to ribosome complexes from our RiboTag-sequencing analysis. Instead of being associated with ribosomes, upregulated Gpr151 mRNA was associated with RBPs such as CSDE1. We found that Gpr151 mRNA binds to CSDE1 through a consensus 
binding sequence conserved in rodent and human genes in its 5'UTR and functions as a noncoding RNA that modulates CSDE1-binding mRNA.

Gpr151 protein levels displayed no increase in mouse DRG tissue when axonal injury was introduced. Instead, the protein levels showed a significant reduction after injury, indicating additional mechanisms for regulating the Gpr151 protein levels. In addition, Gpr151 protein may have a negative role in axonal growth because over-producing Gpr151 protein inhibited axon regeneration in vitro. The enhanced axon regeneration observed in the sciatic nerves of the reduced Gpr151 protein levels observed after nerve injury might be an adaptive response in the DRG neurons to circumvent the inhibitory effect of the Gpr151 pathway. The role of Gpr151 protein in axon regeneration and other injury responses would be an interesting topic in future studies.

RBPs are implicated in diverse events in the nervous system such as neurodevelopment and memory consolidation and also involved in the pathogenesis of neurodegenerative diseases ${ }^{65-68}$. While the main role of RBPs is to regulate the fate of interacting RNA, the functions of RBPs are conversely modulated by interacting with specific regulatory RNAs ${ }^{17}$. Hence, the molecular networks of transcripts and their interacting RBPs need to be delineated in order to correctly understand functional outcome of transcriptomic changes in a specific cellular response. Although we focused on CSDE1 as an interacting RBP of Gpr151-5'UTR, there were other RBPs identified in the mass analysis that putatively interact with the 5'UTR. For example, the interaction of the 5'UTR with NonO was confirmed by pull-down assays where the binding affinity was unaffected by the competitor containing the CSDE1-specific binding sequence in Gpr151-5'UTR. Therefore, 
527 with CSDE1. Although it is unclear whether the interaction with NonO and other RBPs has 528 regulatory roles, we suggest that CSDE1 is a major functional target of Gpr151-5'UTR in axon regeneration because the ability of the 5'UTR to promote regeneration is aborted by deleting the CSDE1-binding motif.

Evidence builds for mRNA functioning as cncRNA with both protein-dependent and independent roles, although the role in axon-injury signaling has not been reported ${ }^{21,22}$. In the present study, we identified Gpr151 as a new cncRNA in the axon regeneration pathway, based on the observation that its mRNA expression and ribosome-association is greatly uncoupled. As there were many other injury-responsive DEGs with the disconnected ribosomal targeting, more genes might be identified as cncRNA involved in the regenerative response. Likewise, our understandings of the DEG functions in other cellular responses may be broadened by examining the potential non-coding roles of their mRNA as regulators of the interacting RBPs. In addition, we suggest investigating the UTR of these DEGs as a potential region responsible for the non-coding function. With this approach, we suggested another single-exon gene, Sox11, as a cncRNA gene regulating axon regeneration, based on a retrospective re-analysis of our previously published dataset. Sox11 is an injury-responsive gene with a potential role in axon regeneration likely through its 5'UTR, while its protein may employ different mechanisms in regulating regeneration. In addition, the 14-3-3 protein family gene Ywha-x also exhibited features of a cncRNA. 14-3-3 proteins are known to play an important role in regulating axon regeneration ${ }^{69}$. In the present study, the 14-33 protein family mRNA (Ywha-x mRNA) exhibited a dramatic release from CSDE1 when Gpr1515'UTRm was overexpressed, although the protein levels did not change (Supplementary information S6), which suggests that this RNA may interact with RBPs other than ribosomes. This means that both its protein and the mRNA itself are involved in the regulation of regeneration, though this needs to be investigated further. regeneration. In addition, overexpressing the engineered form of 5'UTR for enhanced CSDE1binding dramatically improves CNS axon regeneration in an optic nerve injury model. Therefore, we present the engineered 5'UTR of Gpr151 as a potential tool for the manipulation of the 
regenerative potential of neurons. Gpr151 mRNA is thus considered to be an RNA modulator that

556 regulates CSDE1-RNA interaction through its 5'UTR and that has a function that is distinct from its 557 protein in an axon regeneration paradigm.

558 


\section{Acknowledgements}

560 We thank Dr. Aaron DiAntonio and Dr. Valeria Cavalli (Washington University in St. Louis) for 561 critical reading of the manuscript. This work was supported by the Samsung Research Funding 562 \& Incubation Center of Samsung Electronics under Project Number SRFC-MA1802-07.

563

564 Author Contributions

565 Conceptualization, J.L., J.E.S., and Y.C.; Methodology, Formal Analysis, and Investigation, B.L., 566 J.L., Y.J., H.K., M.K., J.E.S., and Y.C.; Resources, Funding Acquisition, Y.C.; Supervision and 567 Project Administration, J.E.S. and Y.C.; Data Curation and Visualization, J.L., J.E.S., and Y.C.; 568 Writing - Original Draft, B.L., J.L., Y.J., J.E.S., and Y.C.; Writing - Review \& Editing, J.E.S. and 569 Y.C.

570

571 Declaration of Interests

572 The authors declare no conflict of interest. 
575 Resources Table

\begin{tabular}{|c|c|c|}
\hline REAGENT or RESOURCE & SOURCE & IDENTIFIER \\
\hline \multicolumn{3}{|l|}{ Antibodies } \\
\hline Rabbit polyclonal Anti HA-ChIP Grade & Abcam & $\begin{array}{l}\text { Cat\#ab9110; } \\
\text { RRID: } \\
\text { AB_307019 }\end{array}$ \\
\hline Rabbit polyclonal Anti-GPR151 & $\begin{array}{l}\text { AVIVA SYSTEMS BI } \\
\text { OLOGY }\end{array}$ & OAAF06441 \\
\hline Rat monoclonal Anti-alpha tublin(YOL1/34) & $\begin{array}{l}\text { SANTA CRUZ BIOT } \\
\text { ECHNOLOGY }\end{array}$ & $\begin{array}{l}\text { Cat\#sc-5303 } \\
\text { 0; RRID: AB } \\
2272440\end{array}$ \\
\hline Rabbit monoclonal Anti-c-Jun(60A8) & $\begin{array}{l}\text { Cell Signaling Techn } \\
\text { ology }\end{array}$ & $\begin{array}{l}\text { Cat\#9165s; } \\
\text { RRID: } \\
\text { AB_2130165 }\end{array}$ \\
\hline Rabbit polyclonal Anti-STMN2 & Novus Biologicals & $\begin{array}{l}\text { Cat\#NBP1-4 } \\
\text { 9461; RRID: } \\
\text { AB_1001156 } \\
9\end{array}$ \\
\hline Rabbit polyclonal Anti-Beta III tubulin & Abcam & $\begin{array}{l}\text { Cat\#ab1820 } \\
\text { 7; RRID:AB_ } \\
\text { 444319 }\end{array}$ \\
\hline Chicken polyclonal Anti-Beta III tubulin & Abcam & $\begin{array}{l}\text { Cat\#ab4148 } \\
\text { 9; RRID: } \\
\text { AB_727049 }\end{array}$ \\
\hline Mouse monoclonal Anti-GAPDH & $\begin{array}{l}\text { SANTA CRUZ BIOT } \\
\text { ECHNOLOGY }\end{array}$ & $\begin{array}{l}\text { Cat\#sc-3223 } \\
\text { 3; RRID: AB } \\
\text { _627679 }\end{array}$ \\
\hline Rabbit monoclonal Anti-DYKDDDDK tag(D6W5B) & $\begin{array}{l}\text { Cell Signaling Techn } \\
\text { ology Signaling }\end{array}$ & $\begin{array}{l}\text { Cat\#14793; } \\
\text { RRID: } \\
\text { AB_2572291 }\end{array}$ \\
\hline $\begin{array}{l}\text { Goat anti-Mouse lgG }(\mathrm{H}+\mathrm{L}) \text { Secondary Antibody } \mathrm{H} \\
\text { RP conjugate }\end{array}$ & $\begin{array}{l}\text { Thermo Fisher Scien } \\
\text { tific }\end{array}$ & $\begin{array}{l}\text { Cat\#62-652 } \\
\text { 0; RRID: AB } \\
\text { _2533947 }\end{array}$ \\
\hline $\begin{array}{l}\text { Goat anti-Rabbit IgG }(\mathrm{H}+\mathrm{L}) \text { Secondary Antibody } \mathrm{H} \\
\text { RP conjugate }\end{array}$ & $\begin{array}{l}\text { Thermo Fisher Scien } \\
\text { tific }\end{array}$ & $\begin{array}{l}\text { Cat\#65-612 } \\
\text { 0; RRID: AB } \\
\text { _2533967 }\end{array}$ \\
\hline $\begin{array}{l}\text { Goat anti-Rabbit lgG }(\mathrm{H}+\mathrm{L}) \text { Secondary Antibody } \mathrm{Al} \\
\text { exa Fluor }{ }^{\circledR} 488 \text { conjugate }\end{array}$ & $\begin{array}{l}\text { Thermo Fisher Scien } \\
\text { tific }\end{array}$ & $\begin{array}{l}\text { Cat\#A-1103 } \\
\text { 4; RRID: AB } \\
\text { 2576217 }\end{array}$ \\
\hline $\begin{array}{l}\text { Goat Anti-Chicken IgY H\&L (Alexa Fluor® 594) pr } \\
\text { eadsorbed }\end{array}$ & abcam & $\begin{array}{l}\text { Cat\#ab1501 } \\
\text { 76; RRID: A } \\
\text { B_2716250 }\end{array}$ \\
\hline $\begin{array}{l}\text { Goat anti-Rabbit lgG }(\mathrm{H}+\mathrm{L}) \text { Secondary Antibody } \mathrm{Al} \\
\text { exa Fluor }{ }^{\circledR} 594 \text { conjugate }\end{array}$ & $\begin{array}{l}\text { Thermo Fisher Scien } \\
\text { tific }\end{array}$ & $\begin{array}{l}\text { Cat\#A-1103 } \\
\text { 7; RRID: AB } \\
\text { _2534095 }\end{array}$ \\
\hline $\begin{array}{l}\text { Goat anti-Rat IgG }(\mathrm{H}+\mathrm{L}) \text { Secondary Antibody HRP } \\
\text { conjugate }\end{array}$ & $\begin{array}{l}\text { Thermo Fisher Scien } \\
\text { tific }\end{array}$ & $\begin{array}{l}\text { Cat\#62-952 } \\
\text { 0; RRID: AB } \\
\text { 22533965 }\end{array}$ \\
\hline
\end{tabular}




\begin{tabular}{|c|c|c|}
\hline pAAV-shRNA-EGFP-U6-5'UTRm & Vectorbuilder & $\begin{array}{l}\text { AAV9SP(VB1 } \\
81206-1015 \\
\text { ysj)-C }\end{array}$ \\
\hline \multicolumn{3}{|l|}{ Biological Samples } \\
\hline \multicolumn{3}{|l|}{ Chemicals, Peptides, and Recombinant Proteins } \\
\hline Vectashield antifade mounting medium & Vector Labs & $\begin{array}{l}\text { Cat\#H-1000; } \\
\text { RRID: AB_ } \\
2336789\end{array}$ \\
\hline Vectashield antifade mounting medium & Vector Labs & $\begin{array}{l}\text { Cat\#H-120 } \\
\text { 0; RRID: AB } \\
2336790\end{array}$ \\
\hline Dynabeads $^{\mathrm{TM}}$ MyOne $^{\mathrm{TM}}$ Streptavidin T1 & $\begin{array}{l}\text { Thermo Fisher Scien } \\
\text { tific }\end{array}$ & Cat\#65601 \\
\hline $\begin{array}{l}\text { cOmplete }{ }^{\mathrm{TM}} \text {, Mini, EDTA-free Protease Inhibitor Co } \\
\text { cktail }\end{array}$ & Roche & $\begin{array}{l}\text { Cat\#469315 } \\
9001\end{array}$ \\
\hline PhosSTOP $^{\text {TM }}$ & Roche & $\begin{array}{l}\text { Cat\#490683 } \\
7001\end{array}$ \\
\hline Cholera Toxin B Subunit & List biological & Cat\#104 \\
\hline \multicolumn{3}{|l|}{ Critical Commercial Assays } \\
\hline RNAscope Multiplex Fluorescent Reagent kit & ACD & Cat\#320850 \\
\hline Lenti-X packaging Single Shots (Ecotropic) & Clontech & Cat\#631276 \\
\hline cDNA-PCR sequencing kit & $\begin{array}{l}\text { Oxford Nanopore Te } \\
\text { chnologies }\end{array}$ & $\begin{array}{l}\text { Cat\#SQK-P } \\
\text { CS109 }\end{array}$ \\
\hline Signaling explorer Antibody Array & ebiogen & $\begin{array}{l}\text { Cat\#SET100 } \\
\text { S }\end{array}$ \\
\hline Phospho explorer Antibody Array & ebiogen & $\begin{array}{l}\text { Cat\#PEX100 } \\
\text { S }\end{array}$ \\
\hline RNAqueous-Micro Total RNA isolation kit & Ambion & $\begin{array}{l}\text { Cat\#AM193 } \\
1\end{array}$ \\
\hline \multicolumn{3}{|l|}{ Deposited Data } \\
\hline \multicolumn{3}{|l|}{ Reference genome } \\
\hline Raw data files for RNA-seq & This paper & \\
\hline \multicolumn{3}{|l|}{ Experimental Models: Primary cultures } \\
\hline Embryonic DRG neurons & This paper & $\begin{array}{l}\text { Mouse: CD- } \\
\text { 1: Crl:CD1(I } \\
\text { CR) }\end{array}$ \\
\hline \multicolumn{3}{|l|}{ Experimental Models: Organisms/Strains } \\
\hline Mouse: Advillin-Cre: Avil ${ }^{t m 2(c r e) F a w a ~}$ & & JAX032536 \\
\hline Mouse: RiboTag: Rpl22 $2^{\text {tm1.1Psam }}$ & $\begin{array}{l}\text { The Jackson Labora } \\
\text { tory }\end{array}$ & JAX029977 \\
\hline Mouse: KO: Gpr151 tm1Dgen & $\begin{array}{l}\text { The Jackson Labora } \\
\text { tory }\end{array}$ & JAX005805 \\
\hline Mouse: C57BL/6J: C57BL/6J & $\begin{array}{l}\text { The Jackson Labora } \\
\text { tory }\end{array}$ & JAX000664 \\
\hline \multicolumn{3}{|l|}{ Oligonucleotides } \\
\hline $\begin{array}{l}\text { siRNA targeting sequence: Gpr151: GCAAAGATT } \\
\text { CTGCTITCAAA }\end{array}$ & $\begin{array}{l}\text { TRC Library Databa } \\
\text { se }\end{array}$ & $\begin{array}{l}\text { TRCN00000 } \\
26286\end{array}$ \\
\hline $\begin{array}{l}\text { siRNA targeting sequence: Csde1: TGCTGTAAGTG } \\
\text { CTCGTAATAT }\end{array}$ & $\begin{array}{l}\text { TRC Library Databa } \\
\text { se }\end{array}$ & $\begin{array}{l}\text { TRCN00002 } \\
76866\end{array}$ \\
\hline $\begin{array}{l}\text { siRNA targeting sequence: Khdrbs1: GCATGTCTT } \\
\text { CATTGAAGTCTT }\end{array}$ & $\begin{array}{l}\text { TRC Library Databa } \\
\text { se }\end{array}$ & $\begin{array}{l}\text { TRCN00001 } \\
02324\end{array}$ \\
\hline
\end{tabular}




\begin{tabular}{|c|c|c|}
\hline $\begin{array}{l}\text { siRNA targeting sequence: Jun: CTCAACTGTGTAT } \\
\text { GTACATAT }\end{array}$ & $\begin{array}{l}\text { TRC Library Databa } \\
\text { se }\end{array}$ & $\begin{array}{l}\text { TRCN00003 } \\
60500\end{array}$ \\
\hline $\begin{array}{l}\text { siRNA targeting sequence: Sox11: TTCGACCTGAG } \\
\text { CTTGAATTC }\end{array}$ & $\begin{array}{l}\text { TRC Library Databa } \\
\text { se }\end{array}$ & $\begin{array}{l}\text { TRCN00003 } \\
65833\end{array}$ \\
\hline $\begin{array}{l}\text { siRNA targeting sequence: ler5: CCATCACTGTGG } \\
\text { CCCAATATA }\end{array}$ & $\begin{array}{l}\text { TRC Library Databa } \\
\text { se }\end{array}$ & $\begin{array}{l}\text { TRCN00002 } \\
48616\end{array}$ \\
\hline \multicolumn{3}{|l|}{ qPCR primer } \\
\hline $\begin{array}{l}\text { Gpr151; Forward: CTGGGTTTGCCGACACCAAT, R } \\
\text { everse: AGAGAGACGGAATGATGGTCC }\end{array}$ & PrimerBank & $33859815 a 1$ \\
\hline $\begin{array}{l}\text { Jun; Forward: CCTTCTACGACGATGCCCTC, } \\
\text { Reverse: GGTTCAAGGTCATGCTCTGTTT }\end{array}$ & PrimerBank & $6754402 a 1$ \\
\hline $\begin{array}{l}\text { Atf3; Forward: GAGGATTITGCTAACCTGACACC, R } \\
\text { everse: TTGACGGTAACTGACTCCAGC }\end{array}$ & PrimerBank & $31542154 a 1$ \\
\hline $\begin{array}{l}\text { RNA sequence(bait): 5'UTR of Gpr151 - } \triangle \text { CSDE1: } \\
\text { CCAACCUAAAGCUACCAUCUGCAGGGAGGAGCU } \\
\text { UG }\end{array}$ & This paper & $\mathrm{N} / \mathrm{A}$ \\
\hline $\begin{array}{l}\text { RNA sequence(bait): 5'UTR of Gpr151 - 4X mutan } \\
\text { t: } \\
\text { ACAAGAAGACAAGAAGACAAGAAGACAAGAAG }\end{array}$ & This paper & $\mathrm{N} / \mathrm{A}$ \\
\hline $\begin{array}{l}\text { RNA sequence(bait): 5'UTR of GPR151 - human: } \\
\text { CAAACCUAAAUAGAAUCUAACUUCUGUAAGAAG } \\
\text { CUGUGAAGAGUG }\end{array}$ & This paper & $\mathrm{N} / \mathrm{A}$ \\
\hline $\begin{array}{l}\text { RNA sequence(bait): 5'UTR of Gpr151 - mouse: } \\
\text { CCAACCUAAACAAGAAGCUACCAUCUGCAGGGAG } \\
\text { GAGCUUG }\end{array}$ & This paper & N/A \\
\hline $\begin{array}{l}\text { RNA sequence(bait): } \mathrm{h} \text { of Gpr151 - mouse: } \\
\text { CCAACCUAAAC }\end{array}$ & This paper & N/A \\
\hline $\begin{array}{l}\text { RNA sequence(bait): 5'UTRm of Gpr151 - mouse: } \\
\text { CCAACCUAAACAAGAAGCUACCAUCUGCAGGGAG } \\
\text { GUCGAAG }\end{array}$ & This paper & N/A \\
\hline $\begin{array}{l}\text { RNA sequence(bait): 5'UTR } \Delta \text { of Gpr151 - mouse: } \\
\text { CCAACCUAAACAAGAAGC }\end{array}$ & This paper & N/A \\
\hline \multicolumn{3}{|l|}{ Recombinant DNA } \\
\hline $\begin{array}{l}\text { Plasmid: FUGW-Flag-Gpr151 (AUG->AUC point m } \\
\text { utation) }\end{array}$ & This paper & $\mathrm{N} / \mathrm{A}$ \\
\hline Plasmid: FUGW-Flag- Gpr151 & This paper & $\mathrm{N} / \mathrm{A}$ \\
\hline Plasmid: pLKO-5'UTR of Sox11 & This paper & $\mathrm{N} / \mathrm{A}$ \\
\hline \multicolumn{3}{|l|}{ Software and Algorithms } \\
\hline Samtools & Li et al., 2009 & $\begin{array}{l}\text { http://samto } \\
\text { ols.sourcefor } \\
\text { ge.net/ }\end{array}$ \\
\hline ImageJ/Fiji for Mac & $\begin{array}{l}\text { Schneider et al., } 20 \\
12\end{array}$ & $\begin{array}{l}\text { https://imag } \\
\text { ej.nih.gov/ij/ }\end{array}$ \\
\hline $\begin{array}{l}\text { Database for Annotation, Visualization and Integrat } \\
\text { ed Discovery (DAVID) }\end{array}$ & $\begin{array}{l}\text { Huang et al., } 2009 a, \\
2009 b\end{array}$ & $\begin{array}{l}\text { https://davi } \\
\text { d.ncifcrf.gov } \\
\text { /tools.jsp }\end{array}$ \\
\hline Origin & OriginLab & $\begin{array}{l}\text { RRID:SCR_0 } \\
14212\end{array}$ \\
\hline Adobe Photoshop CC & Adobe & $\begin{array}{l}\text { RRID:SCR_0 } \\
14199\end{array}$ \\
\hline
\end{tabular}




\begin{tabular}{|l|l|l|}
\hline minimap2 & Li, 2018 & $\begin{array}{l}\text { doi:10.1093/ } \\
\text { bioinformati } \\
\text { cs/bty191 }\end{array}$ \\
\hline
\end{tabular}

577 Resource Availability

578 Further information and requests for reagents and resources should be directed to and will be

579 fulfilled by the lead contact, Yongcheol Cho (ycho77@korea.ac.kr).

\section{Materials Availability}

581 All materials used in this study are commercially available, as specified in the Key Resources Table.

\section{Data and Code Availability}

583 The dataset generated during this study are available at GEO XXXXXX.

584 Experimental Model and Subject Details

585 Primary embryonic DRG neuron cultures: DRG tissues from embryonic 13.5-days mice were 586 dissociated in $0.05 \%$ trypsin-EDTA (Thermo Fisher Scientific, 25300054) and plated on poly-D587 lysine (Sigma, P0899) / laminin (Thermo Fisher Scientific, 23017015)-coated dishes in Neurobasal 588 medium (Thermo Fisher Scientific, 21103049) supplemented with 2\% B-27 (Thermo Fisher 589 Scientific, 17504044), 1\% Glutamax (Thermo Fisher Scientific, 35050061), $1 \mu \mathrm{M}$ 5-fluoro-2'590 deoxyuridine (Sigma, F0503), $1 \mu \mathrm{M}$ uridine (Sigma, U3003), 1\% penicillin-streptomycin (Thermo 591 Fisher Scientific, 15070063), and $50 \mathrm{ng} / \mathrm{ml} 2.5 \mathrm{~S}$ nerve growth factor (Envigo, BT-5017). For the re592 plating assay, cultured neurons were replaced with DMEM (Hyclone, 500mlsh30243.01) / 0.05\% 593 Trypsin-EDTA mixture (1:1) at DIV 5. Neurons were incubated in $37^{\circ} \mathrm{C}, 5 \% \mathrm{CO} 2$ incubator for 5 594 min. Then, neurons were pipetted with culture medium described above. Cells were then 595 dissociated by gentle pipetting and transferred to new Lab-Tek chamber slides coated with poly596 D-lysine/laminin. After re-plating, neurons were incubated for $12 \sim 14$ hours at $37^{\circ} \mathrm{C}$ with $5 \% \mathrm{CO} 2$ 597 then fixed in 4\% paraformaldehyde (Biosesang, P2031) for 15min at room temperature. Neurite 598 lengths were measured and assessed using the Neurite Tracer for ImageJ

599 Animal models: (model organism: name used in paper: allele symbol) Mouse: RiboTag: 600 Rp/22 $2^{\text {tm1.1Psam; }}$ Mouse: Advillin-Cre: Avit ${ }^{\text {m2(cre)Fawa; }}$ Mouse: CD-1: Crl:CD1(ICR); Mouse: C57BL/6J: 601 C57BL/6J; Mouse: KO: Gpr151 ${ }^{\text {tm1Dgen }}$. For in vivo animal studies, all the experiments were carried 602 out in accordance with the Korea University Institutional Animal Care \& Use Committee (KU- 
IACUC). Mice were anesthetized using $3 \%$ isoflurane in oxygen until unresponsive to toe pinch to confirm that the mouse is unconscious and kept on a heating pad for the duration of the surgery. The surgery site was shaved and disinfected using organic iodine of chlorhexidine solution. All surgery instruments were disinfected using autoclave and bead sterilizer. Mice were fed a diet (PicoLab 5053, Purina) and maintained on a 12 hours light/dark cycle (6 am to $6 \mathrm{pm}$ ). Male and female mice were housed in groups of up to 5 mice per cage. Age- and sex-matched male mice were used at the indicated age. The RiboTag mouse carries a ribosomal protein gene with a floxed C-terminal exon followed by an identical exon tagged with hemagglutinin (HA). When RiboTag is crossed to a mouse expressing a cell-type-specific Cre recombinase, expression of the epitopetagged protein is activated in the cell type of interest. A homozygote RiboTag mice $(R p / 22 H A)$ obtained from Jackson Laboratory and Advillin-Cre driver line (Hasegawa et al., 2007) were crossed. Cre positive RiboTag animals (Rp/22HA+/+; advillin-Cre+/-) and the littermate control (Rp/22HA +/+; advillin-Cre-/-) mice were generated by crossing Rp/22HA +/+; advillin-Cre+/- male with $\mathrm{Rp} / 22 \mathrm{HA}+/+$ female. Three-months or older mice were used for sciatic nerve transection surgery. Mice sciatic nerve was unilaterally exposed through a small incision made to the skin and muscles at mid-thigh level. Then, the sciatic nerve was transected by surgical scissors and the incision was closed by nylon suture. The animals were then subjected to post-operation care until euthanized for analysis.

\section{Method Details}

\section{Gene delivery using virus}

Lentivirus-mediated gene delivery was used for knocking down the target mRNA or overexpressing exogenous genes from the embryonic DRG neurons. Lentivirus was produced with Lenti-X packaging Single Shots (Takara, 631275) as following the manual. For in vitro gene delivery, lentivirus was applied to the embryonic DRG neuron cultures at DIV 2. To deliver genes in vivo, adeno-associated virus (AAV, serotype 9) $(10 \mu \mathrm{l})$ was injected to neonatal CD-1 mice (postnatal day 1) by facial vein injection using a Hamilton syringe (Hamilton, 1710 syringe with 33G/0.75-inch small hub removable needle). $10 \mu$ l of AAV virus was tested and the expression of GFP and target genes in sciatic nerve and DRG was confirmed by immunohistochemistry and RT-qPCR analysis. 


\section{Antibody array}

632 Embryonic DRG neurons were rinsed with 1X PBS then collected by gentle centrifugation. The cell 633 pellet was collected at DIV 6. Frozen pellets of eDRG cells were sent to ebiogen (Seoul, South 634 Korea) who carried out antibody array and initial data analyses. The Signaling Explorer Antibody 635 Microarray (SET100) consisting of 1,358 antibodies were supplied by Full Moon BioSystems, Inc., 636 (Sunnyvale, CA, USA).

\section{Ribosome-associated RNA seq}

638 At $24 \mathrm{~h}$ after nerve lesion, L4,5 DRG tissues were dissected from both Cre-positive and negative 639 RiboTag mice. Tissues were homogenized in lysis buffer (1\% NP-40, 20mM HEPES-KOH, 5mM $\mathrm{MgCl}_{2}, 150 \mathrm{mM} \mathrm{KCl}, 1 \mathrm{mM}$ DTT, SUPERase In (Thermo Fisher Scientific, AM2694), and Complete EDTA-free Protease Inhibitor Cocktail (Sigma, 11873580001)) in the presence of cycloheximide

642

643

644

645

646 (Sigma, C7698-1G), rapamycin (Sigma, R0395), then post-mitochondrial fractions were collected. We followed the TRAP protocol as described ${ }^{70}$. Pre-cleared ribosome-mRNA complexes were immunoprecipitated by an anti-HA antibody and Dynabeads Protein G (Thermo Fisher Scientific, 10004D). Total RNA was extracted from the ribosome-mRNA complexes using a RNeasy mini kit (Qiagen, 217084) followed by in-column DNase treatment to remove genomic DNA contamination. The RNA samples were examined for quantity and quality using Nanodrop.

\section{Immunoprecipitating RNA binding proteins}

At $24 \mathrm{~h}$ after nerve lesion, L4,5 DRG tissues were dissected from mice. Tissues were homogenized in TRAP lysis buffer. CSDE1 was immunoprecipitated by anti-CSDE1 antibody pre-bound to Dynabeads Protein G (Thermo Fisher Scientific, 10004D) from total $82 \mu \mathrm{g}$ input lysates for 16 hours at 4'C. The precipitants were washed 5-times using DynaMag-2 (Thermo Fisher Scientific, 12321D) and subjected to reverse transcription for quantitative real time PCR.

\section{Library preparation and nanopore sequencing analysis}

Nanopore libraries were prepared from total RNA combined using the nanopore PCR cDNA sequencing Kit (SQK-PCS109, Oxford Nanopore Technologies) according to manufacturer's instructions. The VN primer was annealed to the RNA to target poly A tail, then first-strand cDNA was synthesized by Maxima H Minus Reverse Transcriptase (Thermo Fisher Scientific, EP0752). 
659 The RNA-cDNA hybrid was then purified using Agencourt AMPure XP magnetic beads (Beckman

660 Coulter, A63880). PCR was performed using 2x LongAmp Taq Master Mix (New England Biolabs, M0287S) to select full-length transcripts followed by a second purification step using Agencourt beads (as described above). The purified cDNA was resuspended by adding $12 \mu$ Elution Buffer and resuspending the beads, incubating at room temperature for $10 \mathrm{~min}$, pelleting the beads again, and transferring the supernatant (pre-sequencing mix) to a new tube. Then the Rapid Adapter was ligated to the cDNA library. Nanopore sequencing was performed as per manufacturer's guidelines using R9.4 SpotON flow cells (FLO-MIN106, ONT) with MinION sequencer. MinION sequencing was controlled using Oxford Nanopore Technologies MinKNOW software as following the manual. Following basecalling, nanopore read data were aligned to the Mus musculus reference (GRCm38.p6, GCA_000001635.8) and transcriptome using MiniMap2. Note that following mapping, all SAM files were parsed to sorted BAM files using SAMtools v1.3.1. For direct RNA sequencing, libraries were prepared from total RNA by using the Nanopore Direct RNA sequencing Kit (SQK-RNA002, Oxford Nanopore Technologies) according to manufacturer's instructions. The RT adapter was annealed to the RNA for reverse transcription, then reverse-transcribed RNA was then purified using Agencourt RNAClean XP magnetic beads (Beckman Coulter, A63880). The purified RNA was eluted from the RNAClean beads (included in the kit) in $21 \mu$ l Elution Buffer included in the kit. Then the Sequencing Adapter was ligated to the library.

\section{PNS axon regeneration assay}

678 For pre-conditioning injury, the right sciatic nerve of age- and sex-matched mice was crushed by forceps and L4,5 DRGs were dissected from spinal cord at the indicated days after injury. Adult DRGs were dissociated using Liberase TM (Roche, 5401119001), DNase I (Sigma, 11284932001) and bovine serum albumin (Sigma, A2153) and trypsin-EDTA for $15 \mathrm{~min}$ in each condition at $37^{\circ} \mathrm{C}$. Dissociated DRGs were triturated gently by pipetting and plated in DMEM (Hyclone, 500mlsh30243.01) with 10\% FBS (Thermo Fisher Scientific, 16000044), 1\% penicillinstreptomycin, (Thermo Fisher Scientific, 15070063) and 1\% Glutamax (Thermo Fisher Scientific, 35050061) on culture dishes coated with poly-D-lysine (Sigma, P0899) and laminin (Thermo Fisher 
dissected at 3 days after crush injury and dissected, sectioned and immunostained with TUJ1 antibody and anti-SCG10 antibody. To visualize the regenerating axons in a single image, multiple pictures were taken along the nerve and montaged automatically in microscope (EVOS FL Auto Cell Imaging System, Thermo Fisher Scientific, AMC1000). SCG10 fluorescence intensity was measured along the length of the nerve sections using ImageJ software. An SCG10 intensity plot was drawn with average intensities calculated from 50 pixels. A regeneration index was calculated by measuring the average SCG10 intensity from the injury site to the distal side, which is defined by the position along the nerve length with maximal SCG10 intensity, correlating with TUJ1 labeling where deformation of the nerve and disruption of axons are identified.

\section{CNS axon regeneration assay}

For CNS axon regeneration assay in vivo from optic nerve injury model, 1.5 ul of AAV was injected with pulled glass needle to vitreous of eye. The conjunctiva from the orbital part of the eye was cleared in order to expose the optic nerve, which was crushed for 3 seconds with Dumont \#5 forceps (Fine Science Tools, 11254-20) and special care was taken not to damage the vein sinus. To avoid desiccation of the eye, a saline solution was applied before and after optic nerve crush. For cholera toxin b (CTB) axon tracing, 1\% atropine sulfate solution (Bauch \& Lomb) was applied to the eye to induce pupil dilation. A pulled glass needle was introduced in the vitreous through the ora serrate and $2 \mu \mathrm{l}$ of $2 \mu \mathrm{g} / \mu \mathrm{l}$ CTB (Thermo Fisher Scientific, C34777) was injected. For optic nerve fixation and sectioning, mice were sacrificed at two days after CTB injection and eyes and optic nerves altogether were fixed by immersion in 4\% paraformaldehyde solution for 2 hours. After being washed three times in PBS, eyes were transferred to $30 \%$ sucrose solution for 24 hours at 4'C. Optic nerves were then dissected out with micro scissors (Fine Science Tools, 15070-08), sectioned at $11 \mu \mathrm{m}$ in the cryostat and mounted in mounting medium ProLong Gold (Thermo Fisher Scientific, P36931). Optic nerve sections were imaged with EVOS FL Auto Cell Imaging System. Numbers of regenerating axons at different distances from the injury site were estimated following the published protocol described by Park et al., 2008. The numbers of regenerating axons crossing lines set at $0.2,0.5,0.8$ and $1 \mathrm{~mm}$ from the injury site were quantified in 5 different slices per optic nerve using ImageJ. The cross-sectional width of the optic nerve was used to estimate the number 
of regenerating axons per $\mu \mathrm{m}$. The total number of regenerating axons per each optic nerve at

716 certain distance from the injury site $\left(\Sigma \mathrm{ad}_{\mathrm{d}}\right)$ was estimated using the following formula: $\Sigma \mathrm{ad}_{\mathrm{d}}=\pi \mathrm{x}$

717 (optic nerve radius) ${ }^{2} \times$ [average axons $/ \mu \mathrm{m}$ ] / $11 \mu \mathrm{m}$. For statistical analysis, the numbers of

718 regenerating axons from control and 5'UTRm-expressing mice at each distance were compared

719 using Student's t test.

\section{Fluorescent in situ hybridization}

721 Gpr151 RNA was detected by a pair of target probe (RNAscope Probe-Mm-Gpr151, ACD, 317321) following the manufacture's instructions. L4,5 DRG tissues were fixed in 4\% paraformaldehyde and permeabilized. The fixed sample tissues were cryo-blocked with OCT compound and sectioned at a $10 \mu \mathrm{m}$ thickness with cryotome. The sections were dehydrated with $50 \%, 70 \%$ to $100 \%$ Ethanol for $5 \mathrm{~min}$ each at room temperature, followed by air dry for $5 \mathrm{~min}$ at room temperature. Tissue section was incubated in Protease 4 (ACD, from the kit RNAscope, 322000) solution for 15 min at room temperature. To wash, phosphate-buffered saline was applied five times to the tissue section. Target probe was pre-warmed at $40^{\prime} \mathrm{C}$ and then the probe was applied to tissue section and incubated for 2 hours in $40^{\prime} \mathrm{C}$. Slide was then washed by wash buffer (ACD, from the kit RNAscope, 322000) twice. The fluorescence probes Amp-1-FL, Amp-2-FL and Amp3-FL were applied to tissue section for $30 \mathrm{~min}$ at 40 'C. Finally, Amp-4-FL was applied and incubated for 15 $\min$ at $40^{\prime} \mathrm{C}$. The prepared samples were mounted and analyzed under confocal microscope (Zeiss,

\section{LSM700).}

\section{Biotin-RNA pull down assay and mass spectrometry analysis}

735 All the RNA baits used for pull-down assay were synthesized by IDT. Total protein lysates were 736 prepared from DRG tissues dissected from 6-weeks old CD-1 mice, lysed in lysis buffer (1\% NP$73740,20 \mathrm{mM}$ HEPES-KOH, $5 \mathrm{mM} \mathrm{MgCl}$, $150 \mathrm{mM} \mathrm{KCl,} 1 \mathrm{mM}$ DTT, SUPERase In (Thermo Fisher 738 Scientific, AM2694), and Complete EDTA-free Protease Inhibitor Cocktail (Sigma, 11873580001)). $7391 \mathrm{mg}$ of protein lysates was subjected as an input for each pull-down condition. The quantified 740 protein input was incubated with the indicated biotin-RNA baits for 16 hours at 4'C, followed by incubation with Dynabeads MyOne Streptavidin T1 (Thermo Fisher Scientific, 65601) for additional

7421 hour at 4 ' $\mathrm{C}$ with rotation. The magnetic beads complexes were washed and recovered by magnet 
743 (Thermo Fisher Scientific, 12321D) as following the manufacturer's instructions. Total protein from 744 the precipitated magnetic beads were eluted by incubating at $95^{\prime} \mathrm{C}$ for $10 \mathrm{~min}$ in $1 \mathrm{X}$ SDS-PAGE 745 sampling buffer then subjected to SDS-PAGE separation. For identifying the eluted proteins by 746 mass spectrometry analysis, protein bands from PAGE gel were visualized by Coomassie staining 747 method and sliced to subject to in-gel digestion. All the mass spectrometry analysis including 748 sample preparation were done by YPRC (Yonsei Proteome Research Center, Seoul Korea). 
750 Supplementary figure 1. Western blot analysis of L4,L5 DRG tissues dissected from RiboTag $\mathrm{x}$ Advillin-Cre mice with (+Injury) or without (-Injury) sciatic nerve axotomy. Anti-HA epitope antibody was used to detect RPL22HA protein, related to figure $1 \mathrm{~A}$.

Supplementary figure 2. Visualization of the illumina sequencing results mapped with mouse Gpr151 gene using SeqMonk.

755

Supplementary figure 3. In vitro axon regeneration assay. (A) Representative images of control, 5'UTRm-overexpressing, and 5'UTRm $\triangle$ CSDE1-overexpressing embryonic DRG neurons. Scale bar, $100 \mu \mathrm{m}$. (B) Statistical analysis of regenerating axon length of $(A)(n=254,198,167$ for control, shCSDE1 and shKHDRBS1; ${ }^{* * *} \mathrm{p}<0.001$, ns, not significant by ANOVA followed by Tukey tests; mean $\pm S E M)$. (B) Statistics of average of relative axon length of $(A)(n=64,55,68$ cells for control, 5'UTRm, 5'UTRm $\Delta$ CSDE1; ${ }^{*} p<0.05$, ns, not significant by ANOVA followed by Tukey tests; mean \pm SEM), related to figure $5 \mathrm{~A}$.

Supplementary figure 4. Statistical analysis of regenerating axon length of embryonic neurons of control, shler5, shJun, shSox11 $\left(n=156,79,78,45\right.$ for each condition; ${ }^{* * *} p<0.001$, ns, not significant by ANOVA followed by Tukey tests; mean \pm SEM), related to figure 7A.

Information S1. The list of identified peptides by mass spectrophotometry analysis of figure 4A. Information S2. CSDE1 IP-sequencing result, related to figure 5C.

Information S3. Gene ontology analysis of figure 5D.

Information S4. KEGG pathway analysis of figure 5E.

Information S5. Antibody array analysis of figure 5F.

Information S6. Comparative analysis between CSDE1 IP-seq and antibody array analysis of figure 5G. 


\section{REFERENCES}

775 1. He, Z. \& Jin, Y. Intrinsic Control of Axon Regeneration. Neuron 90, 437-451 (2016).

776 2. Liu, K., Tedeschi, A., Park, K. K. \& He, Z. Neuronal Intrinsic Mechanisms of Axon Regeneration. Annu. Rev. Neurosci. 34, 131-152 (2011).

778

3. Mahar, M. \& Cavalli, V. Intrinsic mechanisms of neuronal axon regeneration. Nat. Rev. Neurosci. 19, 323-337 (2018).

4. Shin, J. E. \& Cho, Y. Epigenetic Regulation of Axon Regeneration after Neural Injury. Mol. Cells 40, 10-16 (2017).

5. Smith, D. S. \& Skene, J. H. A transcription-dependent switch controls competence of adult neurons for distinct modes of axon growth. J. Neurosci. 17, 646-658 (1997).

6. Sun, F. \& He, Z. Neuronal intrinsic barriers for axon regeneration in the adult CNS. Curr. Opin. Neurobiol. 20, 510-518 (2010).

7. Blackmore, M. G. Molecular Control of Axon Growth: Insights from Comparative Gene Profiling and High-Throughput Screening. International Review of Neurobiology 105, (Elsevier Inc., 2012).

8. Ma, T. C. \& Willis, D. E. What makes a RAG regeneration associated? Front. Mol. Neurosci. 8 , $1-13(2015)$.

9. Gunawardana, Y. \& Niranjan, M. Bridging the gap between transcriptome and proteome measurements identifies post-translationally regulated genes. Bioinformatics 29, 3060-3066 (2013).

10. Reinhold, A. K. et al. Differential transcriptional profiling of damaged and intact adjacent dorsal root ganglia neurons in neuropathic pain differential transcriptional profiling of damaged and intact adjacent dorsal root ganglia neurons in neuropathic pain. PLoS One 10, 1-17 (2015).

11. Huang, D. W., Sherman, B. T. \& Lempicki, R. A. Systematic and integrative analysis of large gene lists using DAVID bioinformatics resources. Nat. Protoc. 4, 44-57 (2009).

12. Terman, S. A. Relative effect of transcription-level and translation-level control of protein synthesis during early development of the sea urchin. Proc. Natl. Acad. Sci. U. S. A. 65, 985992 (1970).

13. Liu, Y., Beyer, A. \& Aebersold, R. On the Dependency of Cellular Protein Levels on mRNA Abundance. Cell 165, 535-550 (2016). 
14. Maier, T., Güell, M. \& Serrano, L. Correlation of mRNA and protein in complex biological samples. FEBS Lett. 583, 3966-3973 (2009).

15. Koussounadis, A., Langdon, S. P., Um, I. H., Harrison, D. J. \& Smith, V. A. Relationship between differentially expressed mRNA and mRNA-protein correlations in a xenograft model system. Sci. Rep. 5, 1-9 (2015).

16. Gygi, S. P., Rochon, Y., Franza, B. R. \& Aebersold, R. Correlation between Protein and mRNA Abundance in Yeast. Mol. Cell. Biol. 19, 1720-1730 (1999).

17. Hentze, M. W., Castello, A., Schwarzl, T. \& Preiss, T. A brave new world of RNA-binding proteins. Nat. Rev. Mol. Cell Biol. 19, 327-341 (2018).

18. Van Nostrand, E. L. et al. A large-scale binding and functional map of human RNA-binding proteins. Nature $583,711-719(2020)$.

19. Chen, L. et al. CELF RNA binding proteins promote axon regeneration in C. elegans and mammals through alternative splicing of syntaxins. Elife 5, 1-26 (2016).

20. Donnelly, C. J. et al. Limited availability of ZBP1 restricts axonal mRNA localization and nerve regeneration capacity. EMBO J. 30, 4665-4677 (2011).

21. Kumari, P. \& Sampath, K. CncRNAs: Bi-functional RNAs with protein coding and non-coding functions. Semin. Cell Dev. Biol. 47-48, 40-51 (2015).

22. Sampath, K. \& Ephrussi, A. CncRNAs: RNAs with both coding and non-coding roles in development. Development 143, 1234-1241 (2016).

23. Sanz, E. et al. Cell-type-specific isolation of ribosome-associated mRNA from complex tissues. Proc. Natl. Acad. Sci. U. S. A. 106, 13939-13944 (2009).

24. Antolin-Fontes, B. et al. The habenular G-protein-coupled receptor 151 regulates synaptic plasticity and nicotine intake. Proc. Natl. Acad. Sci. U. S. A. 117, 5502-5509 (2020).

25. Holmes, F. E. et al. Targeted disruption of the orphan receptor Gpr151 does not alter painrelated behaviour despite a strong induction in dorsal root ganglion expression in a model of neuropathic pain. Mol. Cell. Neurosci. 78, 35-40 (2017).

26. Jiang, B.-C. et al. Demethylation of G-Protein-Coupled Receptor 151 Promoter Facilitates the Binding of Krüppel-Like Factor 5 and Enhances Neuropathic Pain after Nerve Injury in Mice. J. Neurosci. 38, 10535-10551 (2018).

27. Zurborg, S. et al. Generation and characterization of an Advillin-Cre driver mouse line. Mol. 
Pain 7, 1-10 (2011).

28. Broms, J., Antolin-Fontes, B., Tingström, A. \& Ibañez-Tallon, I. Conserved expression of the GPR151 receptor in habenular axonal projections of vertebrates. J. Comp. Neurol. 523, 359380 (2015).

29. Broms, J. et al. Monosynaptic retrograde tracing of neurons expressing the G-protein coupled receptor Gpr151 in the mouse brain. J. Comp. Neurol. 525, 3227-3250 (2017).

30. Wlaschin, J. J. et al. Dual leucine zipper Kinase is required for mechanical allodynia and microgliosis after nerve injury. Elife 7, 1-19 (2018).

31. Shin, J. E., Ha, H., Kim, Y. K., Cho, Y. \& DiAntonio, A. DLK regulates a distinctive transcriptional regeneration program after peripheral nerve injury. Neurobiol. Dis. 127, 178192 (2019).

32. Wu, S. et al. Dorsal root ganglion transcriptome analysis following peripheral nerve injury in mice. Mol. Pain 12, 1-14 (2016).

33. Marvaldi, L. et al. Importin a3 regulates chronic pain pathways in peripheral sensory neurons. Science (80-. ). 369, 842-846 (2020).

34. Tedeschi, A., Omura, T. \& Costigan, M. CNS repair and axon regeneration: Using genetic variation to determine mechanisms. Exp. Neurol. 287, 409-422 (2017).

35. Shin, J. E., Geisler, S. \& DiAntonio, A. Dynamic regulation of SCG10 in regenerating axons after injury. Exp. Neurol. 252, 1-11 (2014).

36. Shin, J. E. et al. SCG10 is a JNK target in the axonal degeneration pathway. Proc. Natl. Acad. Sci. U. S. A. 109, E3696-705 (2012).

37. Ju Lee, H. et al. A post-transcriptional program coordinated by CSDE1 prevents intrinsic neural differentiation of human embryonic stem cells. Nat. Commun. 8, (2017).

38. Guo, H. et al. Disruptive variants of CSDE1 associate with autism and interfere with neuronal development and synaptic transmission. Sci. Adv. 5, 1-17 (2019).

39. Moore, K. S. et al. Csde1 binds transcripts involved in protein homeostasis and controls their expression in an erythroid cell line. Sci. Rep. 8, 1-14 (2018).

40. Saltel, F. et al. Unr defines a novel class of nucleoplasmic reticulum involved in mRNA translation. J. Cell Sci. 130, 1796-1808 (2017).

41. Triqueneaux, G., Velten, M., Franzon, P., Dautry, F. \& Jacquemin-Sablon, H. RNA binding 
specificity of Unr, a protein with five cold shock domains. Nucleic Acids Res. 27, 1926-1934 (1999).

42. Wurth, L. et al. UNR/CSDE1 Drives a Post-transcriptional Program to Promote Melanoma Invasion and Metastasis. Cancer Cell 30, 694-707 (2016).

43. Hosack, D. A., Dennis, G., Sherman, B. T., Lane, H. C. \& Lempicki, R. A. Identifying biological themes within lists of genes with EASE. Genome Biol. 4, (2003).

44. Sherman, B. T. et al. DAVID Knowledgebase: A gene-centered database integrating heterogeneous gene annotation resources to facilitate high-throughput gene functional analysis. BMC Bioinformatics 8, 1-11 (2007).

45. Dennis, G. et al. DAVID: Database for Annotation, Visualization, and Integrated Discovery. Genome Biol. 4, (2003).

46. Shin, J. E., Ha, H., Cho, E. H., Kim, Y. K. \& Cho, Y. Comparative analysis of the transcriptome of injured nerve segments reveals spatiotemporal responses to neural damage in mice. $J$. Comp. Neurol. 526, 1195-1208 (2018).

47. Mahar, M. \& Cavalli, V. Intrinsic mechanisms of neuronal axon regeneration. Nat. Rev. Neurosci. 19, 323-337 (2018).

48. Curcio, M. \& Bradke, F. Axon Regeneration in the Central Nervous System: Facing the Challenges from the Inside. Annu. Rev. Cell Dev. Biol. 34, 495-521 (2018).

49. Shin, J. E. et al. Dual Leucine Zipper Kinase Is Required for Retrograde Injury Signaling and Axonal Regeneration. Neuron 74, 1015-1022 (2012).

50. Jankowski, M. P., Miller, L. \& Koerber, H. R. Increased Expression of Transcription Factor SRY-box-Containing Gene 11 (Sox11) Enhances Neurite Growth by Regulating Neurotrophic Factor Responsiveness. Neuroscience 382, 93-104 (2018).

51. Li, Y., Struebing, F. L., Wang, J., King, R. \& Geisert, E. E. Different Effect of Sox11 in Retinal Ganglion Cells Survival and Axon Regeneration. Front. Genet. 9, 1-14 (2018).

52. Norsworthy, M. W. et al. Sox11 Expression Promotes Regeneration of Some Retinal Ganglion Cell Types but Kills Others. Neuron 94, 1112-1120.e4 (2017).

53. Dulin, J. N. et al. Transcriptomic Approaches to Neural Repair. J. Neurosci. 35, 13860-13867 (2015).

54. Tedeschi, A. \& Popovich, P. G. The application of omics technologies to study axon 
regeneration and CNS Repair [version 1; peer review: 3 approved]. F1000Research 8, 1-13 (2019).

55. Kong, G. et al. AMPK controls the axonal regenerative ability of dorsal root ganglia sensory neurons after spinal cord injury. Nat. Metab. 2, 918-933 (2020).

56. Michaelevski, I. et al. Signaling to transcription networks in the neuronal retrograde injury response. Sci. Signal. 3, (2010).

57. Förstner, P. et al. Neuroinflammation after Traumatic Brain Injury Is Enhanced in Activating Transcription Factor 3 Mutant Mice. J. Neurotrauma 35, 2317-2329 (2018).

58. Jiang, B.-C. et al. Identification of IncRNA Expression Profile in the Spinal Cord of Mice following Spinal Nerve Ligation-Induced Neuropathic Pain. Mol. Pain 11, s12990-015-0047 (2015).

59. Stern, S., Sinske, D. \& Knöll, B. Serum response factor modulates neuron survival during

60. Antolin-fontes, B. et al. Across Drug Classes. (2019).

61. Boulos, L. J., Darcq, E. \& Kieffer, B. L. Translating the Habenula—From Rodents to Humans. Biol. Psychiatry 81, 296-305 (2017).

62. Le Foll, B. \& French, L. Transcriptomic Characterization of the Human Habenula Highlights Drug Metabolism and the Neuroimmune System. Front. Neurosci. 12, 1-16 (2018).

63. Gorlich, A. et al. Reexposure to nicotine during withdrawal increases the pacemaking activity of cholinergic habenular neurons. Proc. Natl. Acad. Sci. 110, 17077-17082 (2013).

65. Conlon, E. G. \& Manley, J. L. RNA-binding proteins in neurodegeneration: Mechanisms in

66. Nussbacher, J. K., Batra, R., Lagier-Tourenne, C. \& Yeo, G. W. RNA-binding proteins in neurodegeneration: Seq and you shall receive. Trends Neurosci. 38, 226-236 (2015).

64. Stein, L. M., Yosten, G. L. C. \& Samson, W. K. Adropin acts in brain to inhibit water drinking: potential interaction with the orphan G protein-coupled receptor, GPR19. Am. J. Physiol. Integr. Comp. Physiol. 310, R476-R480 (2016). aggregate. Genes Dev. 31, 1509-1528 (2017).

67. Gopal, P. P., Nirschl, J. J., Klinman, E. \& Holzbaurb, E. L. F. Amyotrophic lateral sclerosislinked mutations increase the viscosity of liquid-like TDP-43 RNP granules in neurons. Proc. Natl. Acad. Sci. U. S. A. 114, E2466-E2475 (2017). 
924 68. Hörnberg, H. \& Holt, C. RNA-binding proteins and translational regulation in axons and growth $925 \quad$ cones. Front. Neurosci. 7, 1-9 (2013).

926 69. Kaplan, A. et al. Small-Molecule Stabilization of 14-3-3 Protein-Protein Interactions Stimulates 927 Axon Regeneration. Neuron 93, 1082-1093.e5 (2017).

928 70. Shigeoka, T. et al. Dynamic Axonal Translation in Developing and Mature Visual Circuits. Cell 929 166, 181-192 (2016).

930 
Figures

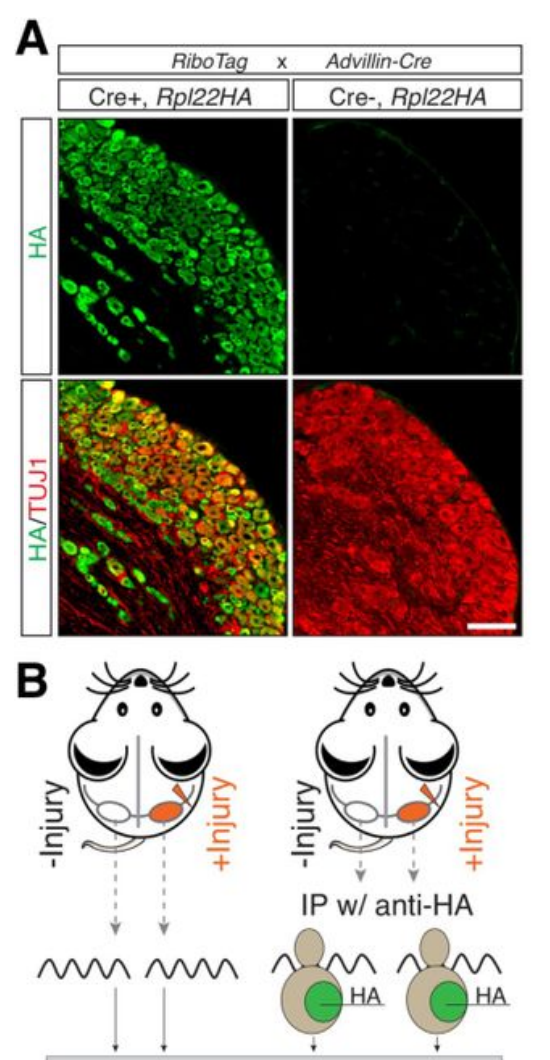

RNA-seq \& comparative analysis
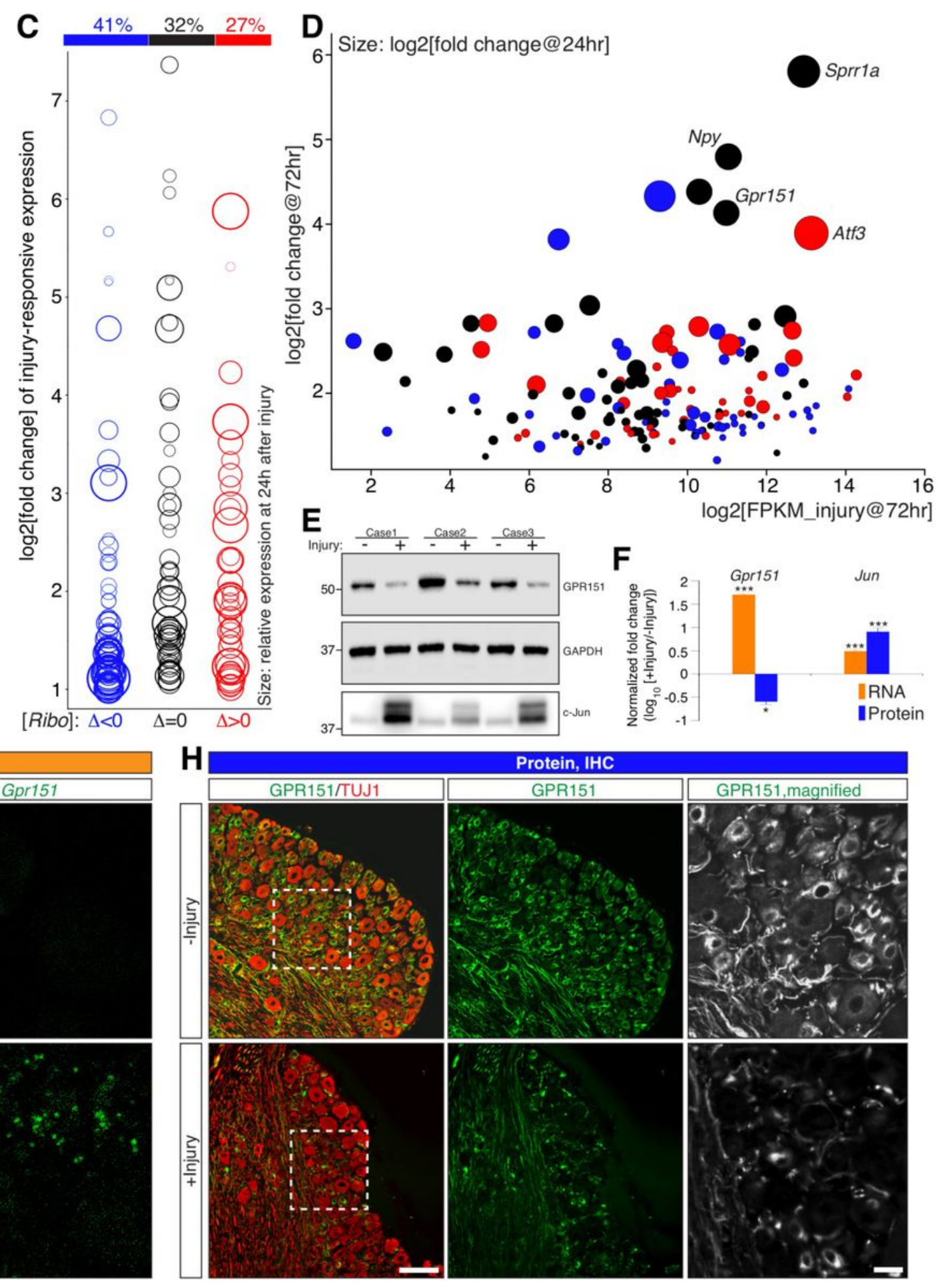

\section{Figure 1}

Gpr151 is the most upregulated and abundant injury-responsive single-exon gene that is not directed to ribosome. (A) Advillin-Cre line crossed with RiboTag mice expresses HA Rpl22 specifically in DRG neurons

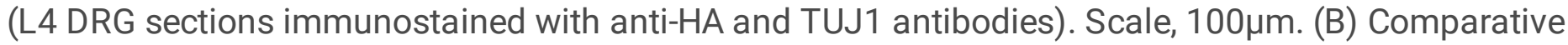
analysis of gene expression and the ribosome115 association. IP, immunoprecipitation. (C) Differential expression (Log2 reads[@injured / @uninjured]) plotted against differential ribosome-association ([Ribo]D 
= reads[@injured- @uninjured]). The size of circle indicates the relative expression level at 24 hours after injury. (D)3D plot of illumina sequencing results from the reference 31 with $x$-axis of log2[FPKM at 72 hours after injury] and y-axis of log2[fold changes at 72 hours after injury]. The bubble sizes indicate $\log 2$ [fold changes at 24 hours]. (E) Western blot analysis of L4,5 DRG tissues with or without sciatic nerve injury. (F) Relative levels of log10[RNA or protein], respectively ( $n=3$; mean $\pm S E M$; ${ }^{*} p<0.05$, ${ }^{* *} p<0.001$ by t-test). (G) FISH analysis of L4 DRG sections with probes to Gpr151 and Gapdh and DAPI. Scale, $5 \mu \mathrm{m}$. (H) Immunohistochemistry of L4 DRG sections prepared at 24 hours after sciatic nerve injury, stained with anti-GPR151 antibody (green) and TUJ1 antibody (red). Scale bar, $100 \mu \mathrm{m}$. 

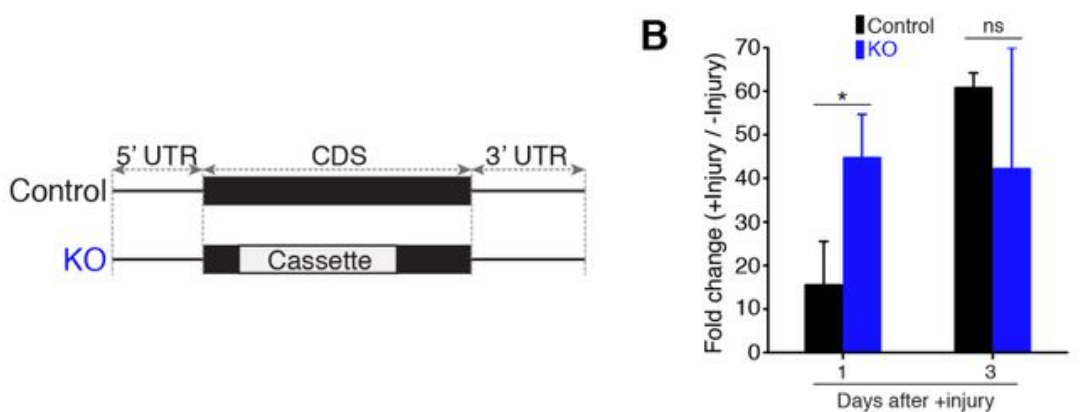

C
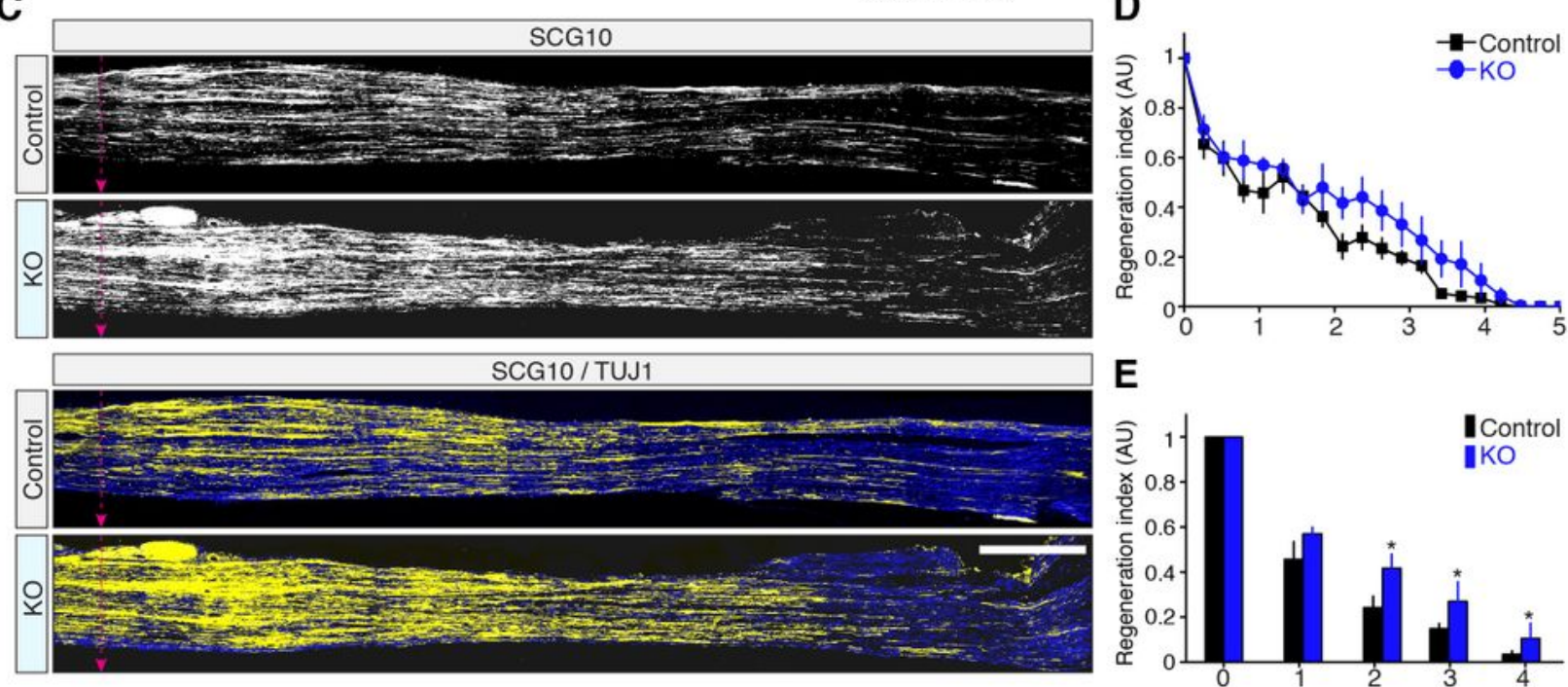

$\mathbf{F}$
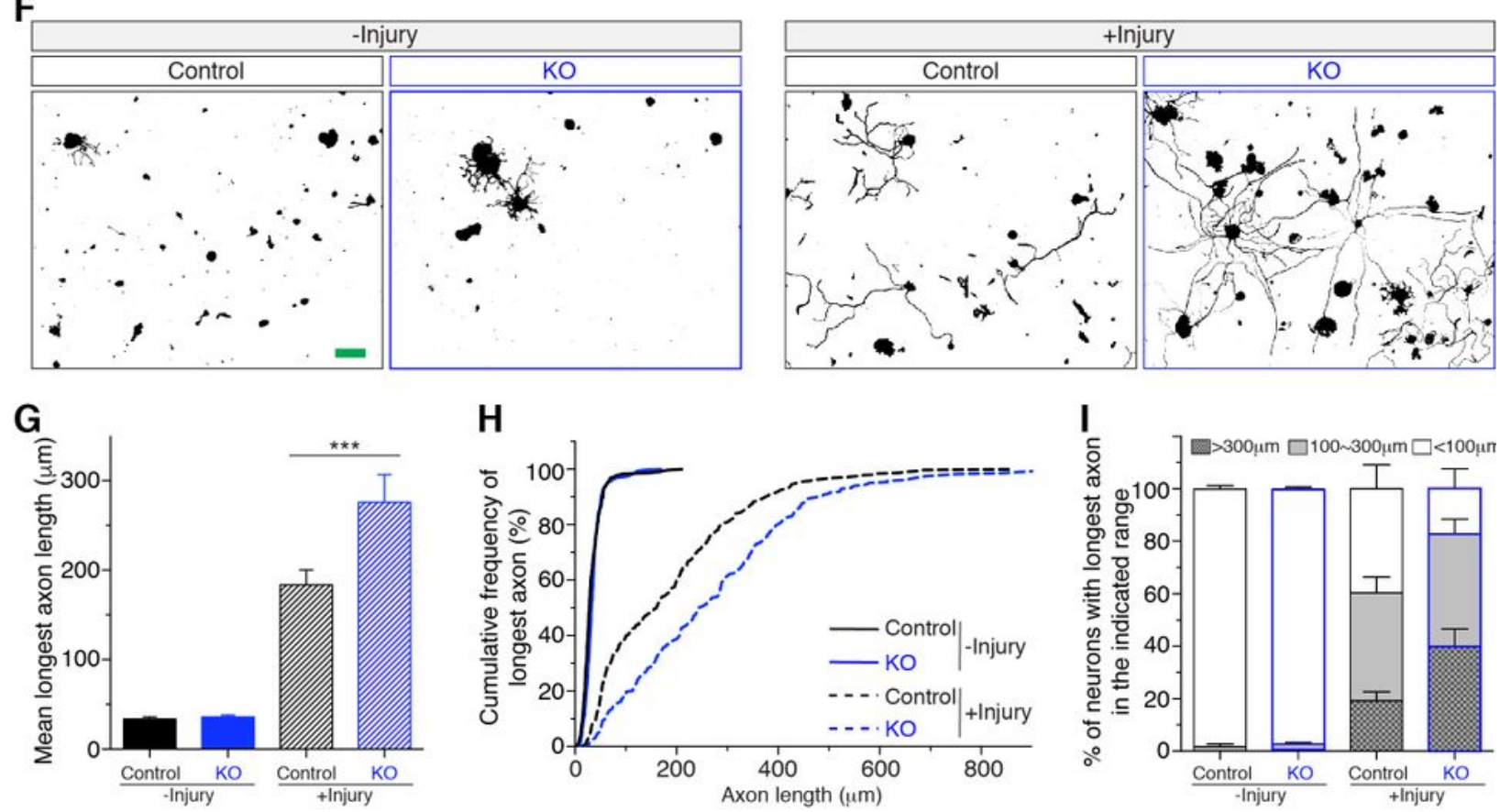

Figure 2

Gpr151 protein-null mice have no impairment of axon regeneration. (A) Schematic diagram of Gpr151 gene in control or targeted knockout (KO) mice. (B) Average fold changes of control or mutant Gpr151 mRNA levels at 1 or 3 days after sciatic nerve axotomy ( $n=3$ for each; $* 00.05$, ns, not significant, ANOVA followed by Tukey tests). (C) In vivo axon regeneration assay. Sciatic nerves from control or Gpr151 protein-null mice (KO) were crushed and dissected at 3 days after injury, immunostained with anti-SCG10 


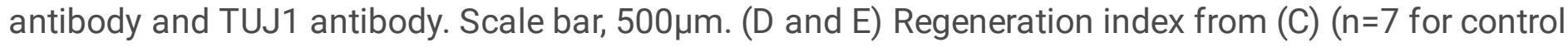
and $n=5$ for $K O$; ${ }^{*}<<0.05$ by $t$-test; mean $\pm S E M$ ). (F) Adult DRG neurons cultured to monitor neuronal preconditioning effect. Mouse L4-5 DRG tissues were dissected at 3 days after sciatic nerve axotomy

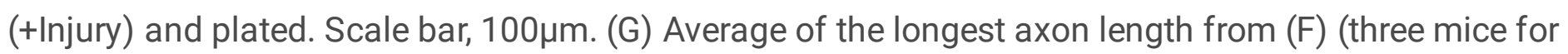
each condition, $304,313,291,283$ cells for each condition; $* \star \star p<0.001$ by ANOVA followed by Tukey tests). (H) Cumulative frequency of the longest axon length from (F). (I) Percentage of neurons in three categories of the longest axon length.

A
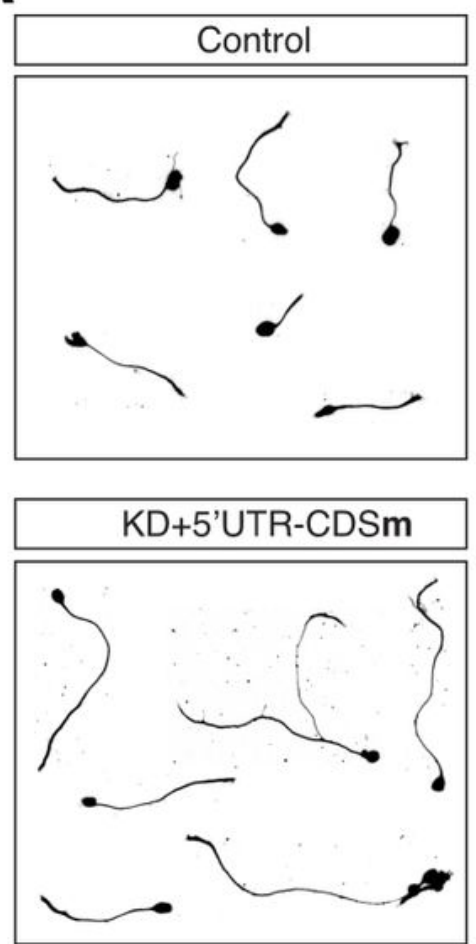

$\mathbf{F}$
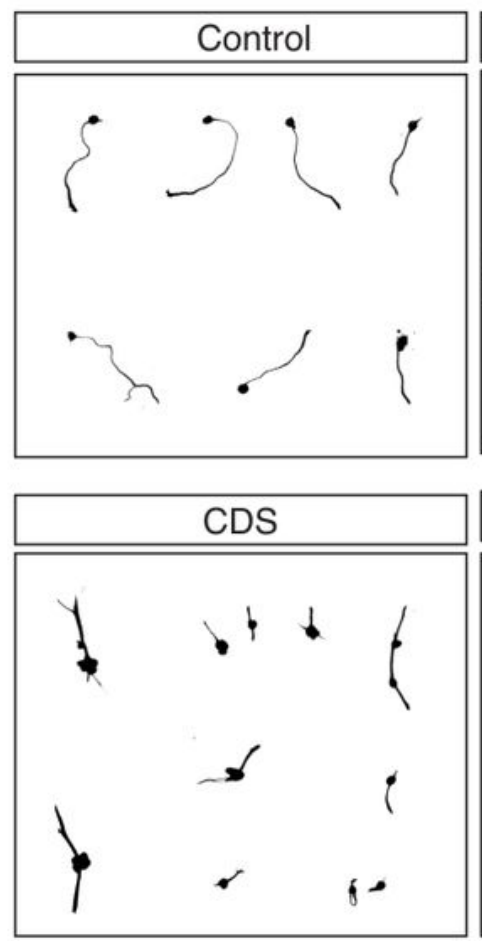
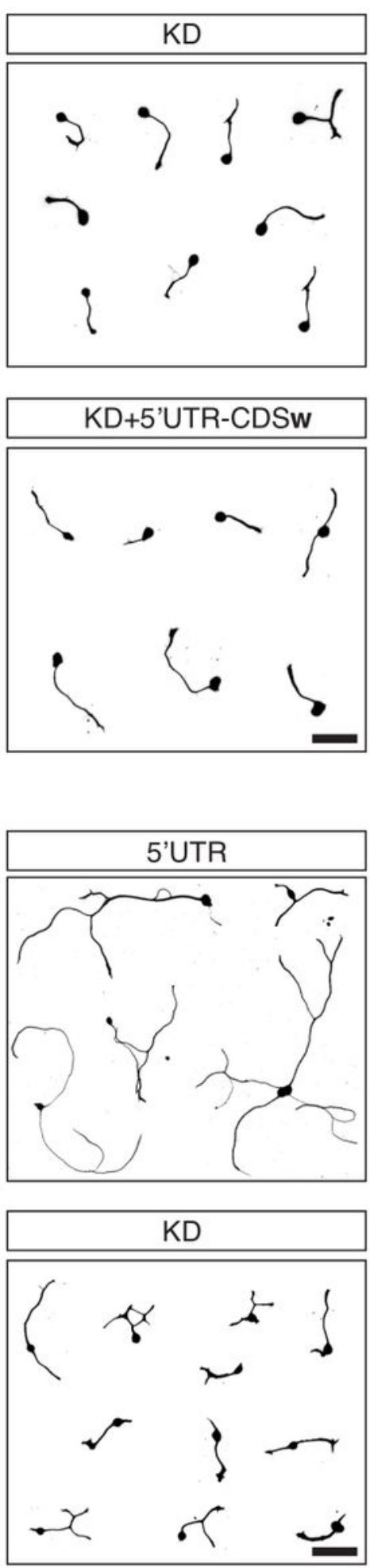

B
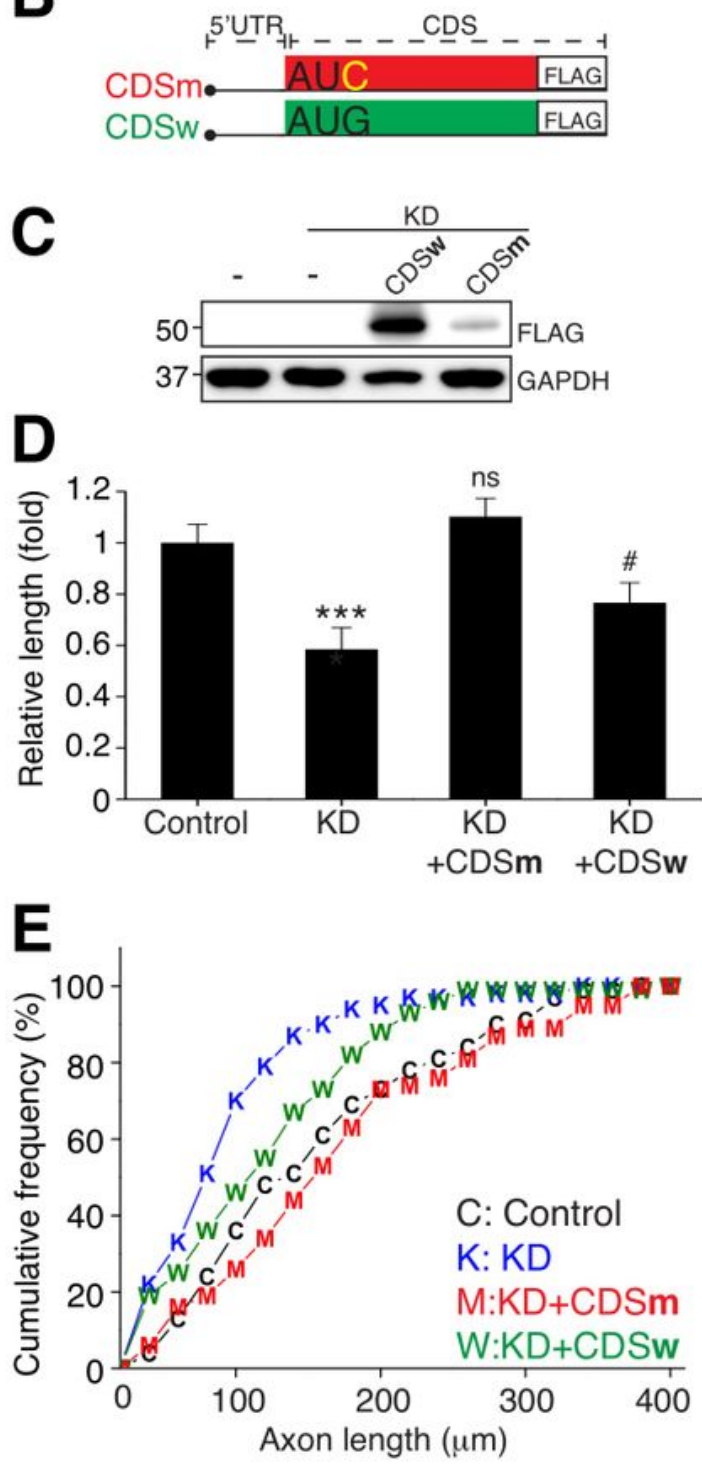

G

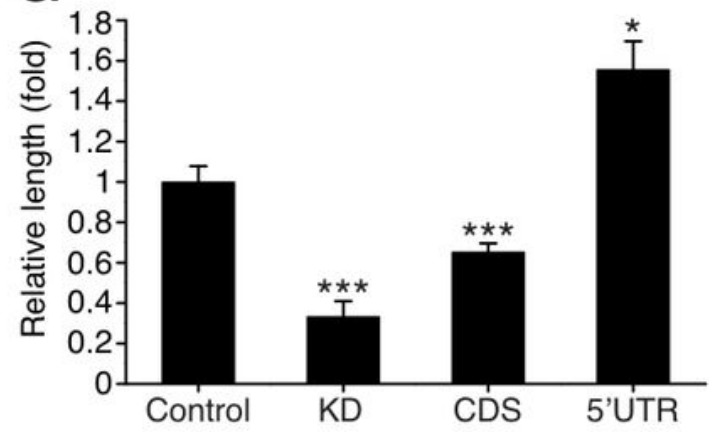




\section{Figure 3}

Gpr151 mRNA is required for axon regeneration, while its protein inhibits axonal growth. (A) In vitro axon regeneration assay of embryonic DRG neurons. Control, Gpr151- knockdown (KD), Gpr151-knockdown (KD) with Gpr151-5'UTR-AUC mutant overexpression (5'UTR-CDSm), and Gpr151-knockdown (KD) with

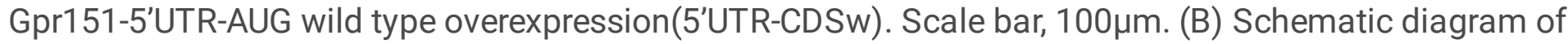
Gpr151-constructs of CDSm and CDSw. AUC and AUG indicate the start codon of protein-coding sequence (CDS). 5'UTR indicates 5'-untranslated region of Gpr151 gene. (C) Western blot analysis validating overexpression level of the constructs CDSm and CDSw shown in (B). Anti-FLAG epitope antibody was used for western blot analysis. (D) Statistical analysis of (A). Average of relative axonal length ( $n=67,63,67,62$ for each condition; ${ }^{* \star} p<0.001$, $\# p=0.05$ by ANOVA followed by Tukey tests). (E) Cumulative frequency of (A). (F) In vitro axon regeneration assay of embryonic DRG neurons. Control, 5'UTR of Gpr151 overexpression (5'UTR), protein-coding sequence overexpression (CDS), and Gpr151knockdown (KD). (G) Statistical analysis of $(F)$. Average of relative axonal length $(n=160,147,267,161$ cells for each condition; ${ }^{*} p<0.05,{ }^{* \star *} p<0.001$ by ANOVA followed by Tukey tests). 
A $\frac{\text { Bait: }}{\text { Control } 5^{\prime} U T R} \quad$ B

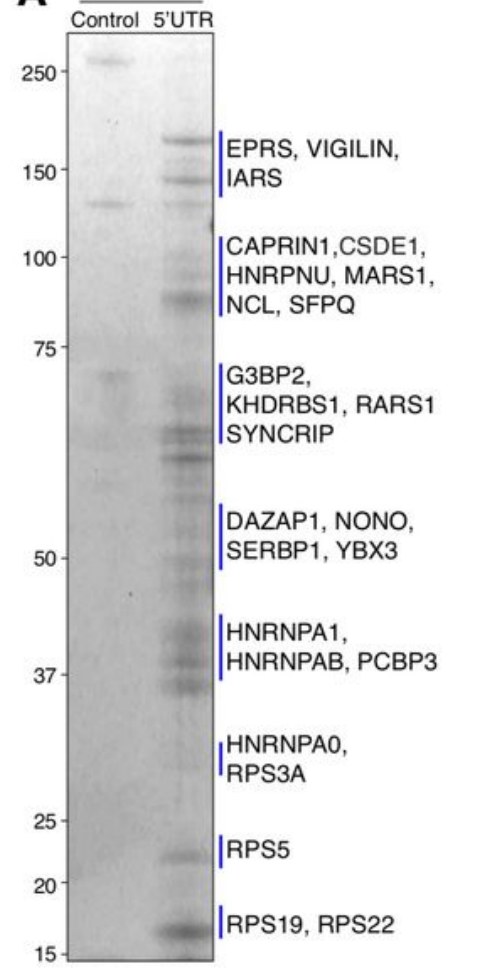

Mouse CCAACCTAAACAAGÄGCTACCATCTGCAGGGAGG-----AGCTTGATG

Rat ACCAACCTAATAAGAAGCTAACATCTGCAGGGAGG-----AGCTGGATG

Human CAAACCTAAATAAGAA'TCTAACTTCTGTAAGAAGCTGTGAAGAGTGATG

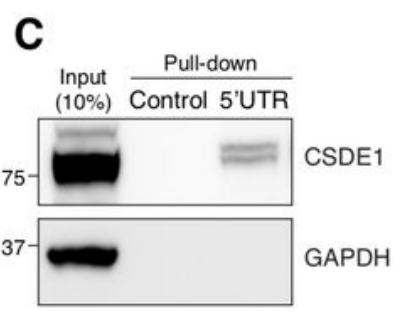

E

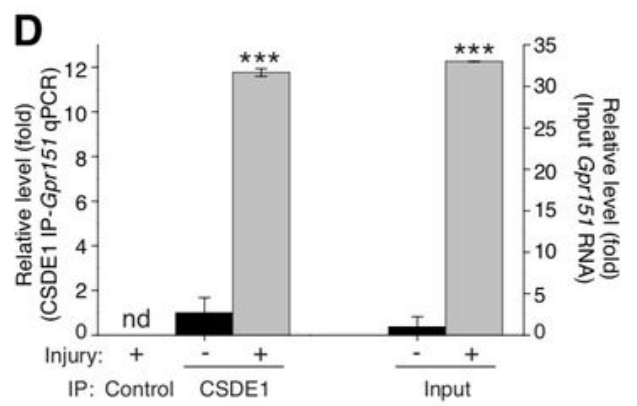

5'UTRWT CAAGAA

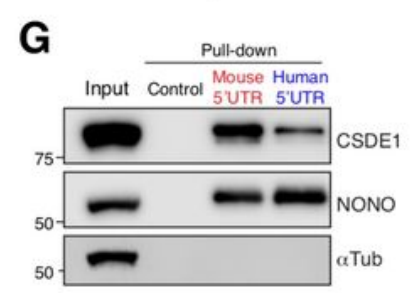

4X ACAAGAAGACAAGAAGACAAGAGACAAGAAG

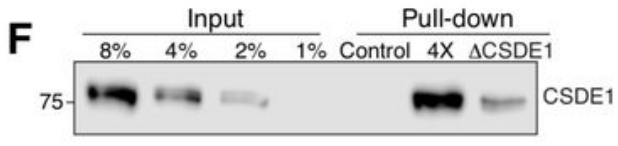

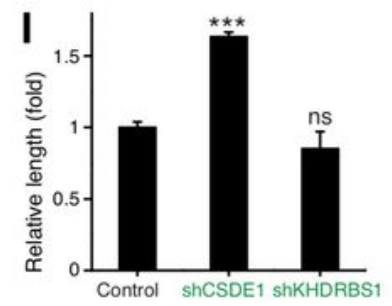

H
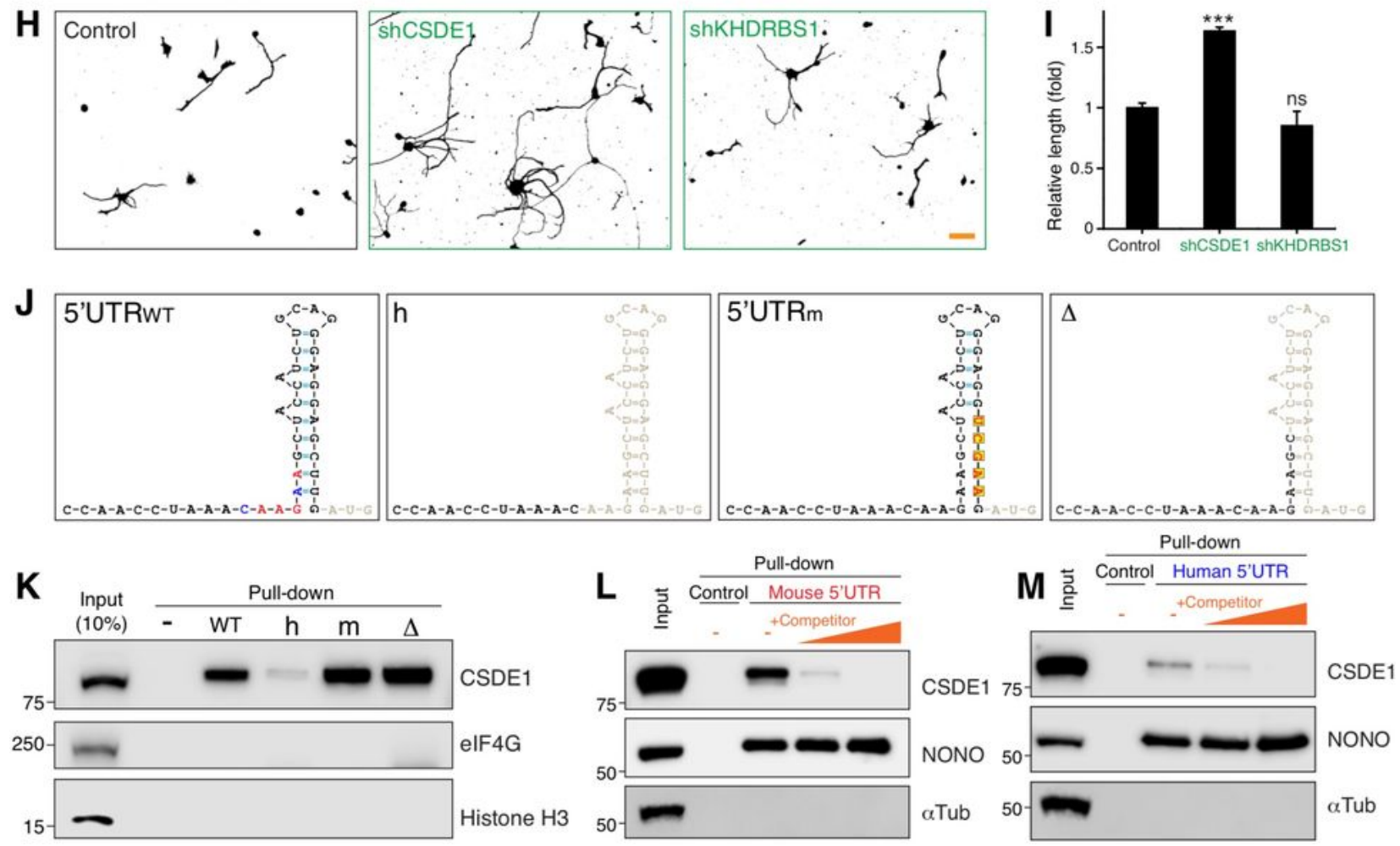

Figure 4

CSDE1 is a negative regulator of axon regeneration interacting with 5'UTR of Gpr151 mRNA. (A) Coomassie staining of SDS-PAGE of 5'UTR-binding proteins. (B) Alignment of 5'UTR sequences of mouse, rat and human GPR151 gene. Green box, nAAGnA, CSDE1- binding consensus motif, yellow shadow, the start codon of Gpr151 CDS. (C) Western blot analysis of 5'UTR pull-down assay. (D) Relative folds of Gpr151 mRNA levels analyzed by RT-qPCR $(n=3$, *** $p<0.001$, nd, not determined by t-test; 
mean $\pm S E M)$. (E) Illustration of the artificial RNA sequences of DCSDE1 or $4 X$ mutant. (F) Western blot analysis of pull-down assay with the baits, DCSDE1 or 4X mutant. (G) Western blot analysis of pull-down assay with the baits, mouse 5'UTR or human 5'UTR of GPR151. (H) In vitro axon regeneration assay from control, CSDE1 knockdown (shCSDE1) and KHDRBS1 knockdown (shKHDRBS1) embryonic DRG neurons. Scale bar, $100 \mu \mathrm{m}$. (I) Statistical analysis of regenerating axon length of $(H)(n=254,198,167$ for control, shCSDE1 and shKHDRBS1; $* \star \star p<<0.001$, ns, not significant by ANOVA followed by Tukey tests; mean \pm SEM). (J) Illustrations of the secondary structures of 5'UTR of Gpr151 wild type (5'UTRWT), no CSDE1-binding motif (h), single-stranded CSDE1-binding motif (5'UTRm) and no stem (D) mutant. (K) Western blot analysis of pull-down assay with the baits of $(\mathrm{J})$. ( $\mathrm{L}$ and $\mathrm{M})$ Western blot analysis of pull-down assay with the competitor $\mathrm{D}$ for mouse and human $5^{\prime} \mathrm{UTR}$. 


\section{B}

A

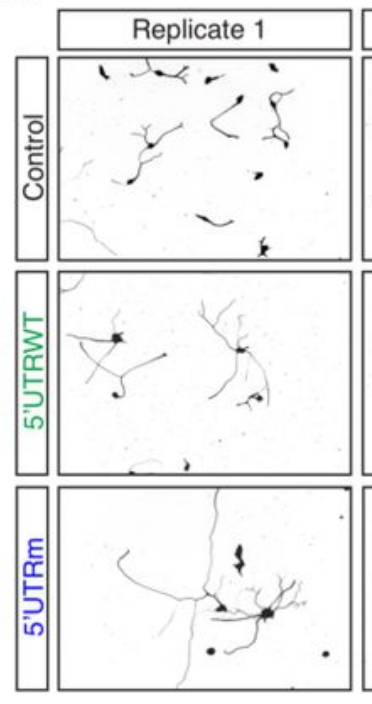

D

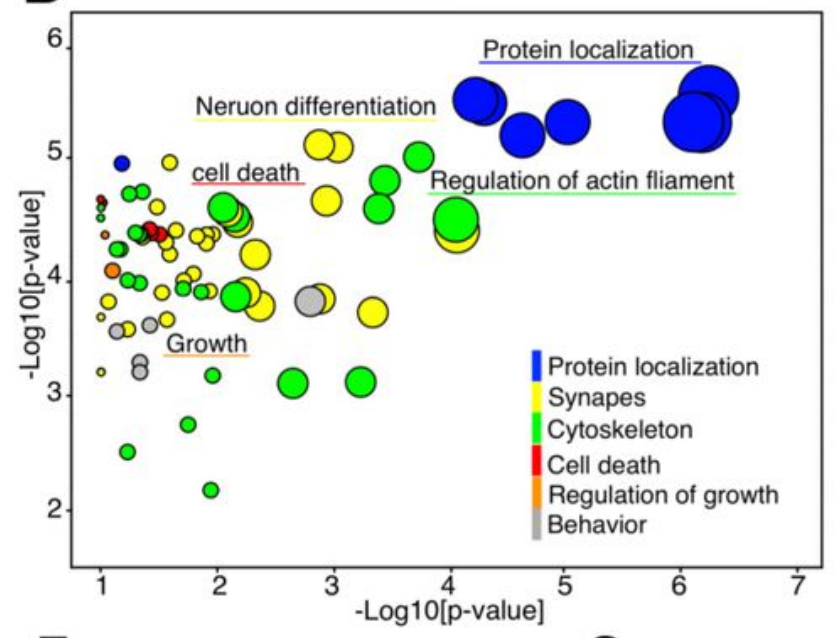

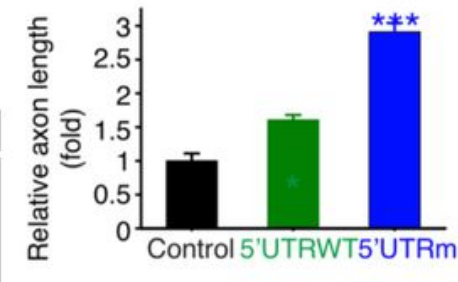

C
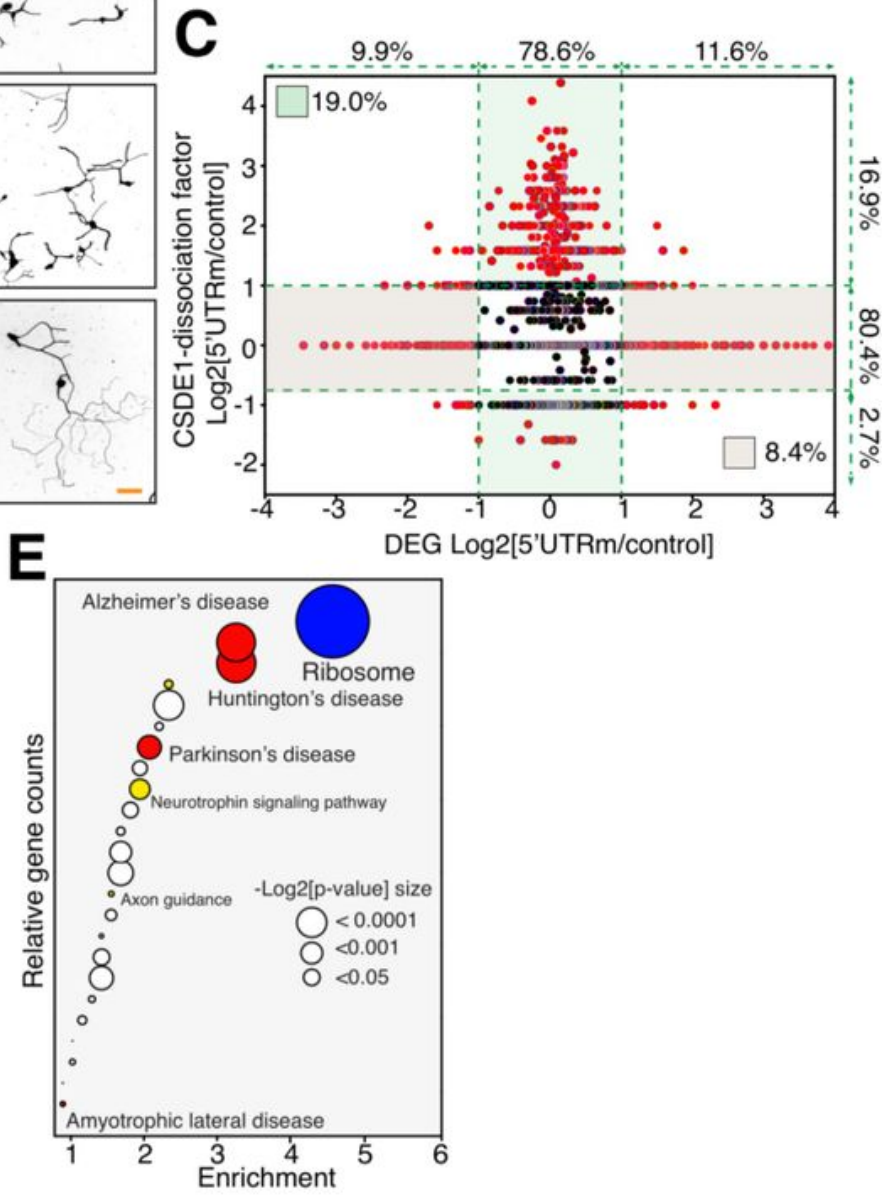

G

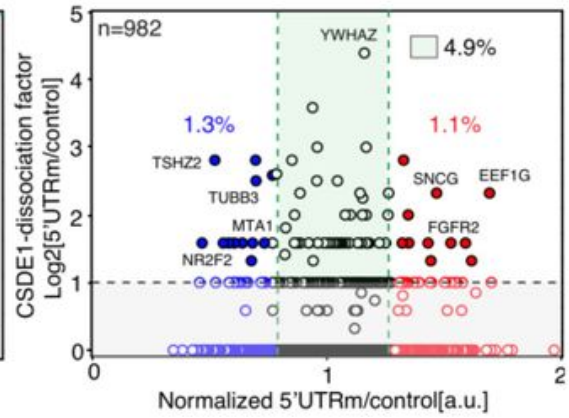

Figure 5

Expressing engineered 5'UTR of Gpr151 mRNA modulates CSDE1-RNA interaction, resulting in dissociation of an RNA group related to distinct biological processes. (A) In vitro axon regeneration assay of embryonic DRG neurons expressing control vector, 5'UTR of Gpr151(5'UTRWT) or a mutant 5'UTR with

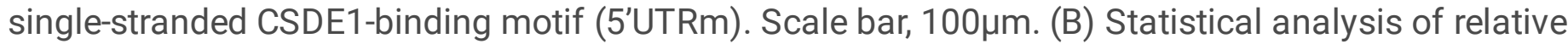
average axon length from $(A)\left(n=97,104,98\right.$ cells for control, $5^{\prime}$ UTRWT and $5^{\prime} U T R m ;{ }^{*} p<0.05,{ }^{* \star \star} p<0.001$ 
by ANOVA followed by Tukey tests; mean士SEM). (C) Two-dimensional plot with the x-axis of log2transformed fold changes of [reads@5'UTRm / reads@control] and the y-axis of. See also supplementary information S2. (D and E) Gene ontology analysis (D) and KEGG pathway analysis (E) of the genes dissociated from CSDE1 by 5'UTRm overexpression, shown in the upper green box in (C). (F) Proteomic analysis of antibody array results with the x-axis of normalized log2-transformed values in control and $y$ axis of normalized log2-transformed values in 5'UTRm. The color red and blue indicates upregulated or downregulated target protein by $30 \%$ or more, respectively. Percentages indicate the relative ratios of the colored targets of total 1,358 probes. (G) Target proteins in (F) are plotted for the corresponding CSDE1dissociation factor of their mRNA, negative log2-transformed fold changes of CSDE1-IP [reads@5'UTRm / reads@control].

A

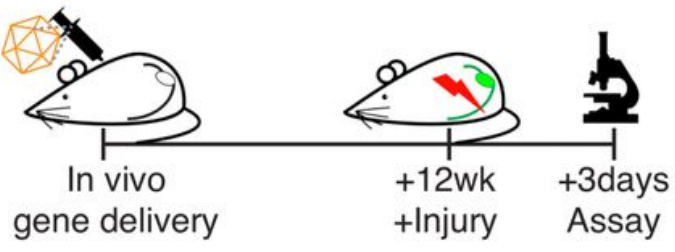

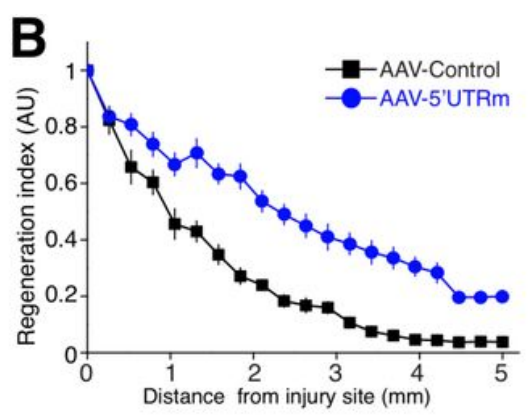

\section{D}
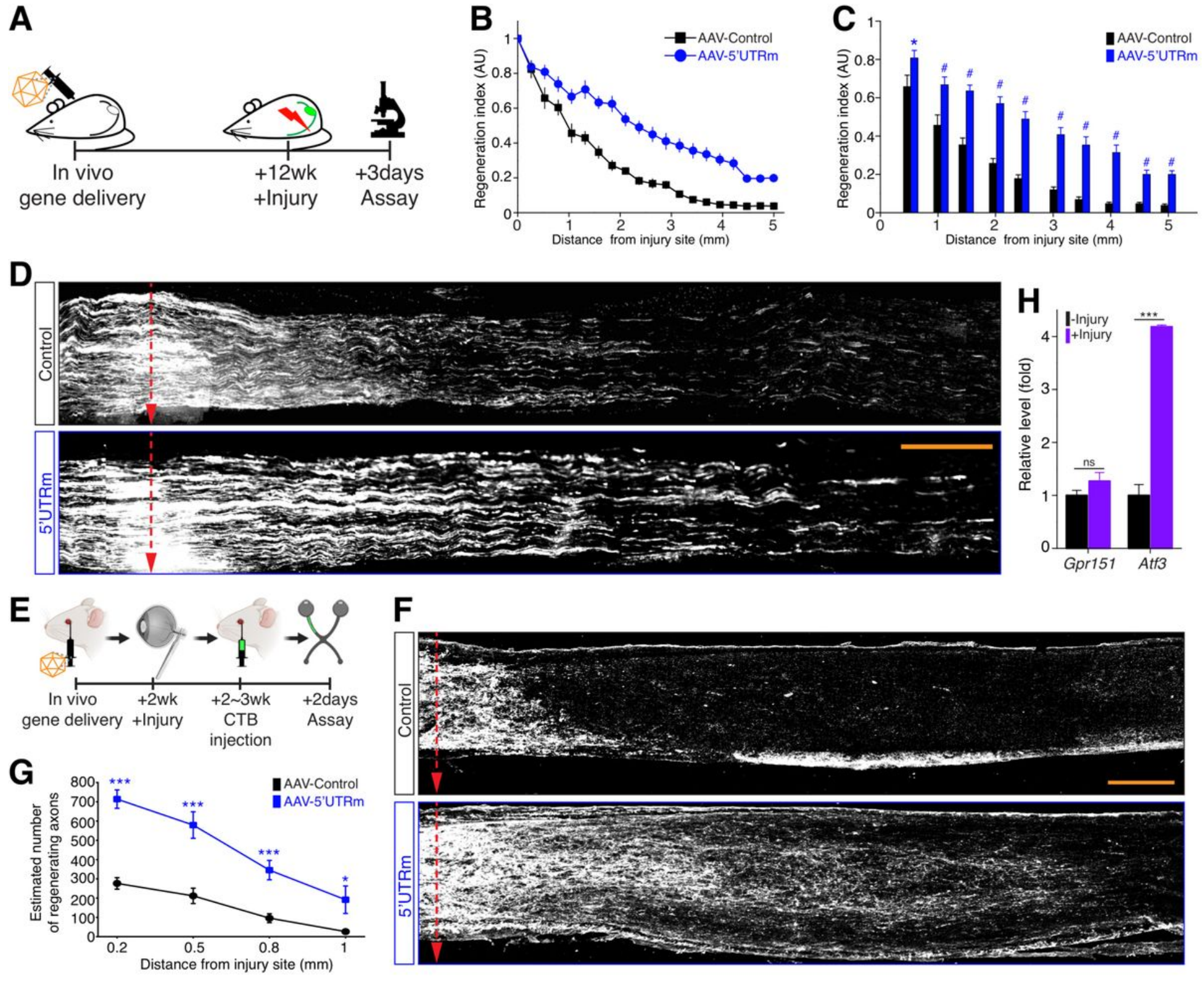

Figure 6

In vivo gene delivery of engineered 5'UTR of Gpr151 mRNA promotes axon regeneration. (A) Experimental scheme of in vivo gene delivery for in vivo axon regeneration assay in mouse sciatic nerves (wk, week(s)). 
( $B$ and $C$ ) In vivo regeneration index from (D) ( $n=8$ for control, 10 for $5^{\prime} U T R m ;{ }^{*} p<0.05, \# p<0.001$ by t-test; mean $\pm S E M)$. (D) In vivo axon regeneration assay from sciatic nerves. Representative longitudinal sections of the sciatic nerves from control or 5'UTRm-expressing mice. Red dotted arrows indicate the

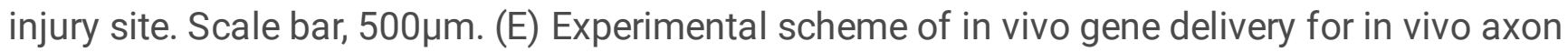
regeneration assay in mouse optic nerves (wk, week(s)). (F) Representative longitudinal sections of optic nerves from control or 5'UTRm-expressing mice. Red dotted arrows indicate the injury site. Scale bar, $200 \mu \mathrm{m}$. (G) Estimated numbers of regenerating axons ( $n=5$ for control, 6 for $5^{\prime} U T R m ;{ }^{*} p<0.05,{ }^{* \star \star} p<0.001$ byt-test; mean \pm SEM). (H) qPCR analysis of Gpr151 and Atf3 from mouse retina with (+Injury) or without (Injury) injury ( $\mathrm{n}=3$ for each condition; $* \star \star \mathrm{p}<0.001$, ns, not significant by $\mathrm{t}$-test; mean $\pm S E M)$.

A

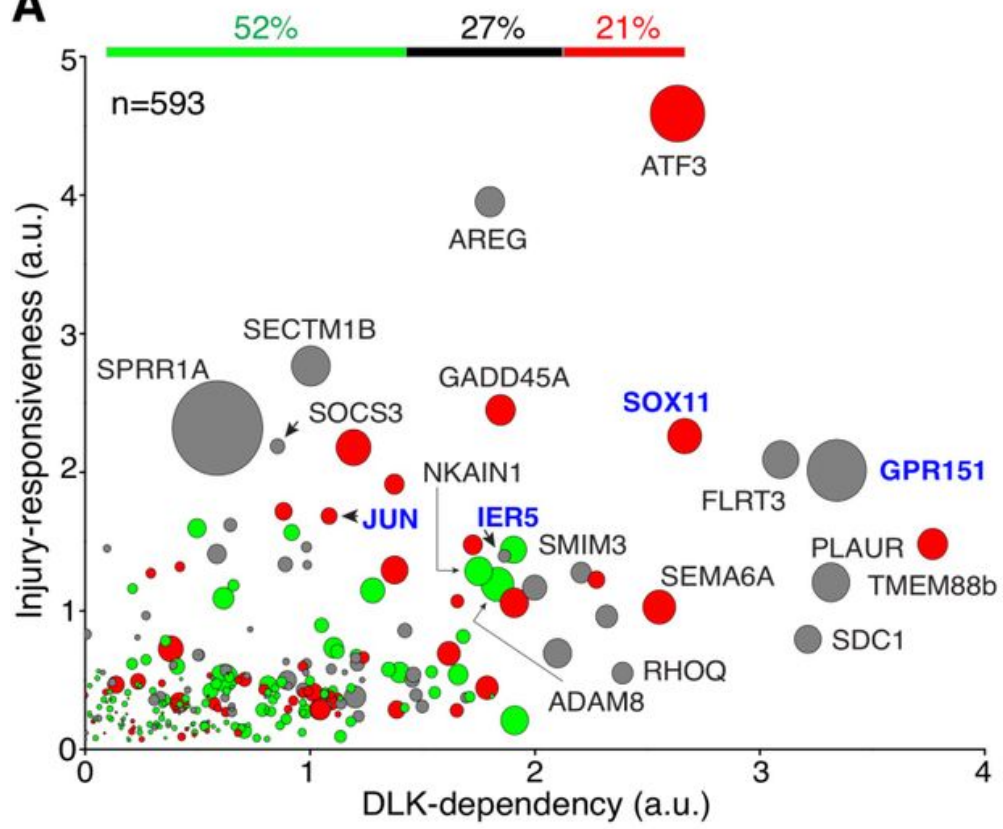

B
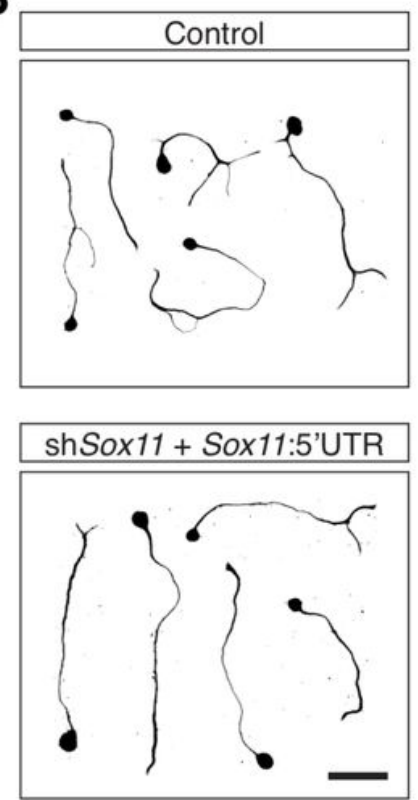
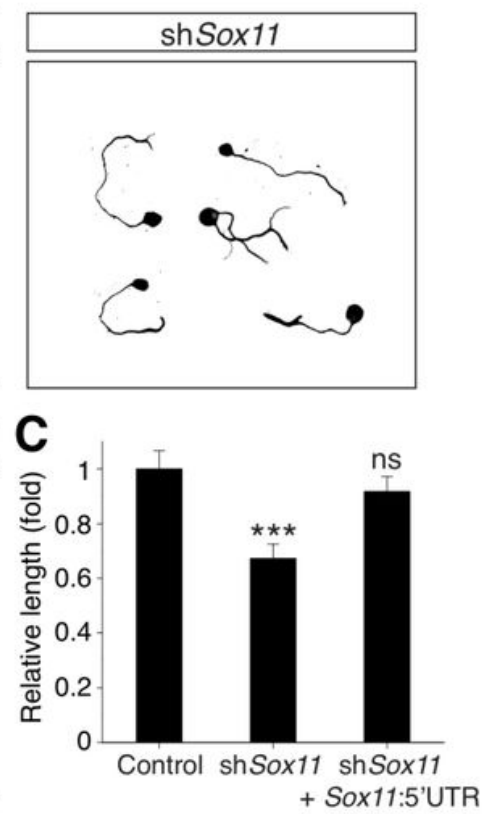

\section{D}

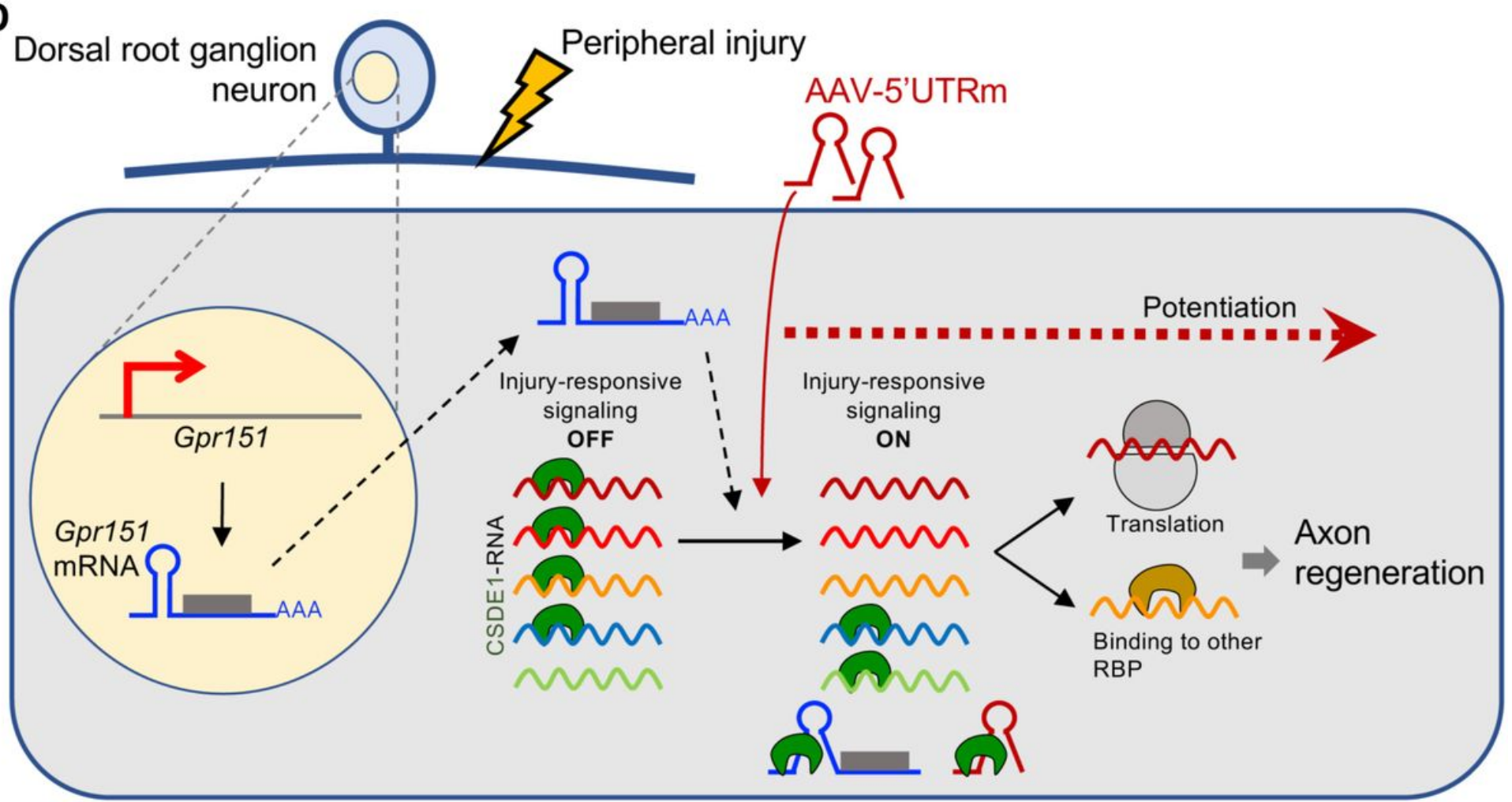




\section{Figure 7}

Retrospective re-analysis of the previously published DEG data suggests 5'UTR of Sox 11 regulates neuronal potential for axon regeneration. (A) Three-dimensional plot with the $x$-axis of DLK-dependency (a.u.), the $y$-axis of injury-responsiveness (a.u.) and the circle sizes of the relative fold change at 72 hours after injury. The colors indicate ribosome-association efficiency; red, increased, black, not changed and green, decreased at 24 hours after injury. Total 593 genes were selected as DLK-dependent injuryresponsive genes. (B) In vitro axon regeneration assay of re-plated embryonic DRG neurons. Control, Sox11 knock-down (shSox11) and Sox11 knock-down with 5'UTR of Sox11 overexpression (shSox11 + Sox11:5'UTR). Scale bar, $100 \mu \mathrm{m}$. (C) Average relative axon length of (C) $(n=63,86,70$ cells for each; ${ }^{\star * *} p<0.001$, ns, not significant by ANOVA followed by Tukey tests; mean $\left.\pm S E M\right)$. (D) Illustration of the proposed model.

\section{Supplementary Files}

This is a list of supplementary files associated with this preprint. Click to download.

- SEGtableS1MSanalysispeptidelist.xlsx

- SEGtableS25CCSDE1IPseq.xIsx

- SEGtableS35DGO.xIsx

- SEGtableS45EKEGG.xlsx

- SEGtableS55Fantibodyarray.xlsx

- SEGtableS65GAACSDE1.xIsx

- Gpr151SI0219NC.pdf

- nrreportingsummaryNCOMMS2106814.pdf 